Article

\title{
Cyclonic Wave Simulations Based on WAVEWATCH-III Using a Sea Surface Drag Coefficient Derived from CFOSAT SWIM Data
}

\author{
Weizeng Shao ${ }^{1,2, * \mathbb{C}}$, Tao Jiang ${ }^{1}$, Yu Zhang ${ }^{1}$, Jian Shi ${ }^{3}$ and Weili Wang ${ }^{4}$ \\ 1 College of Marine Sciences, Shanghai Ocean University, Shanghai 201306, China; \\ m200200560@st.shou.edu.cn (T.J.); yuzhang@shou.edu.cn (Y.Z.) \\ 2 Key Laboratory of Marine Ecological Monitoring and Restoration Technologies, \\ Ministry of Natural Resources, Shanghai 201206, China \\ 3 College of Meteorology and Oceanography, National University of Defense Technology, \\ Changsha 410073, China; shijian.mil@163.com \\ 4 North China Sea Marine Forecasting Center, Ministry of Natural Resources, Qingdao 266061, China; \\ wangweiliee@hotmail.com \\ * Correspondence: shaoweizeng@mail.tsinghua.edu.cn; Tel.: +86-21-6190-0326
}

\section{check for} updates

Citation: Shao, W.; Jiang, T.; Zhang, Y.; Shi, J.; Wang, W. Cyclonic Wave Simulations Based on WAVEWATCH-III Using a Sea Surface Drag Coefficient Derived from CFOSAT SWIM Data Atmosphere 2021, 12, 1610. https://doi.org/10.3390/ atmos 12121610

Academic Editors: Tinghai Ou, Xuejia Wang and Hengde Zhang

Received: 22 October 2021 Accepted: 30 November 2021 Published: 2 December 2021

Publisher's Note: MDPI stays neutral with regard to jurisdictional claims in published maps and institutional affiliations.

Copyright: (c) 2021 by the authors. Licensee MDPI, Basel, Switzerland. This article is an open access article distributed under the terms and conditions of the Creative Commons Attribution (CC BY) license (https:// creativecommons.org/licenses/by/ $4.0 /)$.

\begin{abstract}
It is well known that numerical models are powerful methods for wave simulation of typhoons, where the sea surface drag coefficient is sensitive to strong winds. With the development of remote sensing techniques, typhoon data (i.e., wind and waves) have been captured by optical and microwave satellites such as the Chinese-French Oceanography SATellite (CFOSAT). In particular, wind and wave spectra data can be simultaneously measured by the Surface Wave Investigation and Monitoring (SWIM) onboard CFOSAT. In this study, existing parameterizations for the drag coefficient are implemented for typhoon wave simulations using the WAVEWATCH-III (WW3) model. In particular, a parameterization of the drag coefficient derived from sea surface roughness is adopted by considering the terms for wave steepness and wave age from the measurements from SWIM products of CFOSAT from 20 typhoons during 2019-2020 at winds up to $30 \mathrm{~m} / \mathrm{s}$. The simulated significant wave height $\left(H_{S}\right)$ from the WW3 model was validated against the observations from several moored buoys active during three typhoons, i.e., Typhoon Fung-wong (2014), Chan-hom (2015), and Lekima (2019). The analysis results indicated that the proposed parameterization of the drag coefficient significantly improved the accuracy of typhoon wave estimation (a $0.49 \mathrm{~m}$ root mean square error (RMSE) of $H_{S}$ and a 0.35 scatter index (SI)), greater than the 0.55 RMSE of $H_{S}$ and $>0.4$ SI using other existing parameterizations. In this sense, the adopted parameterization for the drag coefficient is recommended for typhoon wave simulations using the WW3 model, especially for sea states with $H_{s}<7 \mathrm{~m}$. Moreover, the accuracy of simulated waves was not reduced with growing winds and sea states using the proposed parameterization. However, the applicability of the proposed parameterization in hurricanes necessitates further investigation at high winds $(>30 \mathrm{~m} / \mathrm{s})$.
\end{abstract}

Keywords: typhoon; significant wave height; drag coefficient; WAVEWATCH-III

\section{Introduction}

It is well known that sea surface wind stress plays an important role in the air-sea interactions in the boundary layer [1]. In particular, the rapid change of the drag coefficient under extreme sea states, as in typhoons and hurricanes, results in the inhomogeneity of wind stress [2]. In the last several decades, much effort has been devoted to this topic in numerous studies [3-6]. This is also an essential aspect for improving numerical wave models [7], e.g., WAVEWATCH-III (WW3) [8-11] and Simulating Waves Nearshore (SWAN) [12-14]. According to the study in [15], more than 300 typhoons have passed over the China Seas from 1998 to 2017, and typhoon-induced disasters pose increasingly 
serious threats to coastal areas of China. Therefore, it is important to establish and improve numerical predictions for typhoons.

A third-generation wave model (WAM) [16] has been used since 1990; this model was initially developed by solving the wave action equation [17]. Based on the previous WAM, the WW3 model developed by the National Oceanic and Atmospheric Administration/National Centers for Environmental Prediction (NOAA/NCEP) [18] and a similar wave model named SWAN developed by Delft University of Technology [19] have been available through open-source release. Recently, a global forecast operational system has been successfully proposed at multi-grid scales based on the WW3 model [20]. Several studies have focused on improving the WW3 model through the source terms of parameterizations for wind and swell dissipation [21,22]. In our previous studies, the input/dissipation terms [23], non-linear four wave components (quadruplets), and three wave components (triads) of wave-wave interactions [24] were implemented for typhoon wave simulations using the WW3 model. The dependence of the drag coefficient on the generation of a fetch-limited wave for Typhoon Ivan was investigated using the WW3 model and altimeter data [25]. The results indicated that the existing parameterization with wind speeds up to $30 \mathrm{~m} / \mathrm{s}$ was applicable to the coupled wave and surge models.

In the literature, the wind stress is associated with the roughness of the sea surface, which cannot be directly measured. Practically, sea roughness is usually calculated from the wind speed with the drag coefficient. For many years, the drag coefficient was considered to be a constant [26]; however, it was found that the drag coefficient increases with the wind speed [27] at low and moderate winds ( $5-20 \mathrm{~m} / \mathrm{s})$. Using a combination of laboratory and field data, several previous studies focused on improving the drag coefficient at lowto-moderate winds (i.e., [28]). However, due to the nature of the sea surface in a high state, e.g., huge swells and wave breaking, the dependence of the drag coefficient on waves should be considered [29]. In addition, the general characteristics of wind-induced waves in Taiwan Strait [30,31] have been studied, where the drag coefficients were calculated using a few data from near-shore buoy observations using numeric wave models, concluding that the adopted parameterization of the drag coefficient could improve the wave simulations in typhoons. However, the parameterization of the drag coefficient in typhoons could be further improved through an abundant remote-sensing wave spectrum dataset.

The Chinese-French Oceanic SATellite (CFOSAT) is an international mission organized by the Centre National d'Etudes Spatiales (CNES) of France and the Chinese National Space Agency (CNSA). CFOSAT has the capability of sea surface monitoring [32] with a fine spatial resolution ( $18 \mathrm{~km}$ footprint) as well as synthetic aperture radar (SAR) [33]. The CFOSAT carries two instruments, a rotating fan-beam scatterometer (RFSCAT) [34] and novel Surface Wave Investigation and Monitoring (SWIM) [35] that are used to obtain simultaneous observations of winds and waves. Because the orbit of CFOSAT has a 13-day period and a 99\% coverage of the earth's surface, it is a promising instrument for typhoon and hurricane monitoring through analysis of the wave spectrum. The SWIM onboard CFOSAT has provided a continuous product wave directional spectrum [36] that is specifically designed for global wave observation using six rotating fan-beams at near-nadir incidence angles between $0^{\circ}$ and $10^{\circ}$ with a $2^{\circ}$ bin interval and $360^{\circ}$ azimuth scanning [37]. The CFOSAT SWIM wave spectra are valuable remote-sensing sources for wind and wave analysis [38], and the data can be used for the derivation of the drag coefficient in a numerical model under cyclonic conditions.

With the development of parameterizations for dynamic processes at the air-sea interface, the model-simulated results and the observations will become more consistent. However, due to the inability to obtain accurate data from moored observations during tropical cyclones, the applicability of numerical wave models necessitates further investigation, because the accuracy of model-simulated waves significantly decreases with growing wind speed and sea state. In this study, simultaneous wind and wave spectral data derived from the CFOSAT SWIM during 20 typhoons occurring in the period 2019-2020 in the China Seas were used to develop a parameterization for the drag coefficient, and this then 
employed wave simulations using the WW3 model for three typhoons, i.e., Typhoons Fung-wong (2014), Chan-hom (2015), and Lekima (2019). The simulated results were further validated against the observations from several moored buoys.

The remainder of this article is organized as follows. Section 2 briefly describes the collocated datasets, i.e., forcing fields for numeric modeling as well as the model settings, the measurements from the CFOSAT satellite, and data from moored buoys. Section 3 describes the methodology of the WW3 model for simulating waves and the derivation of the drag coefficient. The dependence of sea surface roughness on the drag coefficient is discussed in this section. Section 4 shows the results from implementing the new parameterization for the drag coefficient in the WW3 model, and the model-simulated $H_{s}$ for the three typhoons is validated against the measurements from moored buoys. Finally, the results are summarized in Section 5.

\section{Datasets}

In this section, the available datasets for this study are briefly introduced; these are of three types: (1) the regular forcing data for wave modeling and the settings of the WW3 model (version 6.07); (2) the wind and wave measurements from the CFOSAT satellite; and (3) the observations from buoys to validate the simulated $H_{s}$.

\subsection{Forcing Data and WW3 Model Settings}

The European Centre for Medium-Range Weather Forecasts (ECMWF) (ERA-5) [39] is an institute for worldwide investigation that continuously provides global atmospheric and marine data at intervals of one hour each day using a $0.25^{\circ}$ grid. Wind and wave parameters (e.g., combined wind and sea swells) are officially released, and these data are applicable for short- and long-term wave distribution analysis for regional seas $[40,41]$ and global seas $[42,43]$. Distortion of the wave height from the ERA-5 wave reanalysis data has been shown, i.e., overestimation at low sea states and underestimation at high sea states [44,45] because of the inaccuracy of ERA-5 wind speed data [46]. Under these circumstances, the ERA- 5 wind speed data cannot be directly employed as the forcing field for wave simulation by the WW3 model. In previous studies concerning typhoon wave simulation [13,23], a composite wind field was reconstructed as "H-E winds", combining ERA data and estimates for strong winds derived from a parametric function called the Holland model [47], which is trained by refitting the shape parameter. The validation of wind speeds against the moored buoy measurements during Typhoon Fung-wong (2014) and Typhoon Chan-hom (2015) yielded a less than $3 \mathrm{~m} / \mathrm{s}$ root-mean-square error (RMSE) with the shape parameter equal to 0.4 (see Figure 5 in [23]). The $0.1^{\circ}$ gridded $\mathrm{H} \neg-\mathrm{E}$ wind vectors at intervals of one hour were utilized as the forcing field, combing $0.1^{\circ}$ gridded winds from the parametric Holland model with the shape parameter equal to 0.4 and the $0.25^{\circ}$ gridded ERA- 5 winds.

The best tracks of Typhoons Fung-wong (2014), Chan-hom (2015), and Lekima (2019) collected from the Japan Meteorological Agency (JMA) are shown in Figure 1a, in which the maximum wind speed in the typhoon moment reached $50 \mathrm{~m} / \mathrm{s}$. The H-E wind map at 01:00 UTC on 10 August 2019 is presented in Figure 1b. The spatial resolution of outputs from the WW3 model is $0.1^{\circ}$ grid at an interval of $30 \mathrm{~min}$. In this study, the spatial coverage of collected typhoon cases are about $300 \mathrm{~km}$ so as to include more samples at a wind speed greater than $20 \mathrm{~m} / \mathrm{s}$ for wave simulations for Typhoons Fung-wong (2014), Chan-hom (2015), and Lekima (2019). 


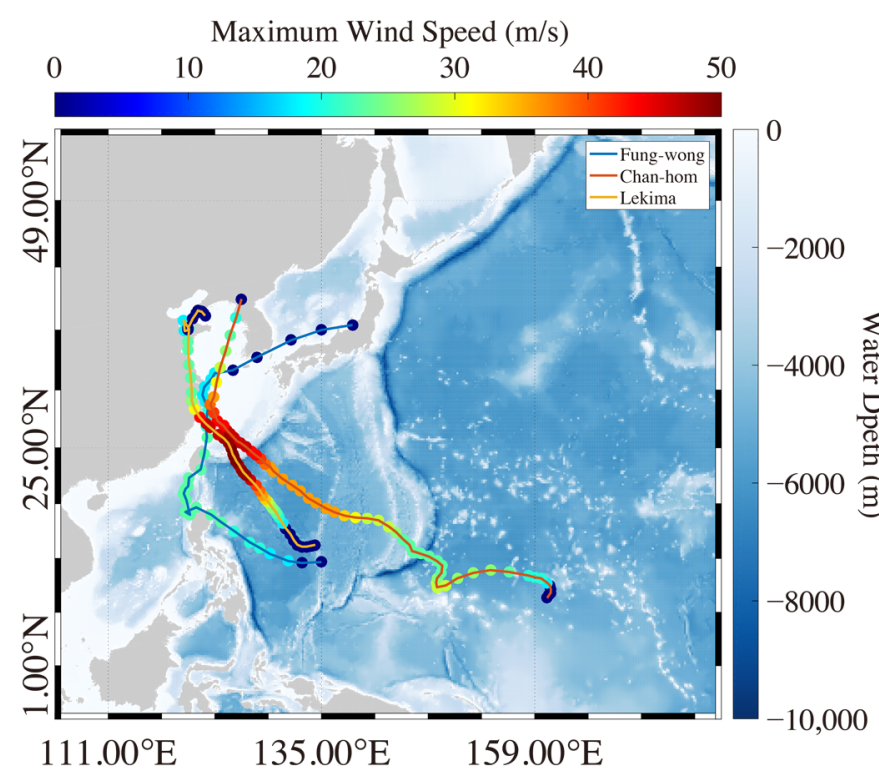

(a)

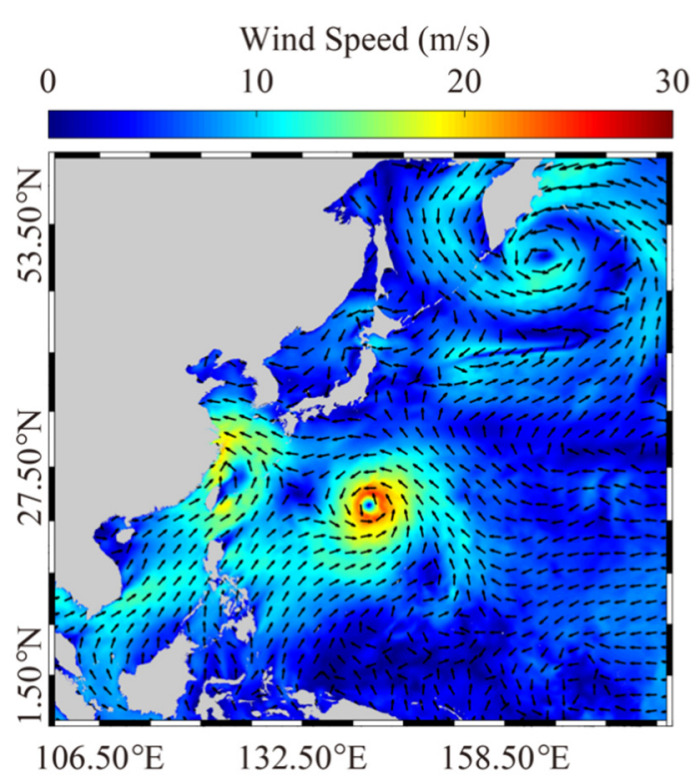

(b)

Figure 1. (a) The tracks of three typhoons with the measurements from moored buoys, overlaid by the General Bathymetry Chart of the Oceans (GEBCO) water depth. (b) The $0.1^{\circ}$ gridded composite wind fields at 01:00 UTC on 10 August 2019.

In this work, the simulated region covering the three typhoon paths in the western Pacific Ocean was set as $5-40^{\circ} \mathrm{N}$ latitude and $100-170^{\circ}$ E longitude. The water depth extracted from bathymetric topography of the General Bathymetry Chart of the Oceans (GEBCO) with $1 \mathrm{~km}$ horizontal resolution was interpolated as a $0.05^{\circ}$ grid. The model was run for April 2014, July 2015, and August 2019. The settings of the WW3 model illustrating the physical processes included input/dissipation source terms by the switch ST2 package [48] with a good performance of the typhoon wave simulations around Zhoushan islands [23], triad wave-wave interactions by the switch TR1 package [49], quadruplet wave-wave interactions by the switch GMD2 package [50], wave breaking by the switch FLD2 package [51], the switch BT1 representing JONSWAP bottom friction formulation [52], and the $0.5^{\circ}$ gridded currents derived from the NCEP Climate Forecast System Version 2 (CFSv2) from the National Center of Atmospheric Research (NCAR) [15]. The settings for the outputs were as follows. The two-dimensional wave spectrum comprised 24 regular azimuthal directions with a $15^{\circ}$ step; the frequency bins were arranged logarithmically between $0.04118 \mathrm{~Hz}$ and $0.7186 \mathrm{~Hz}$ at an interval of $\Delta \mathrm{f} / \mathrm{f}=0.1$; the spatial propagation was characterized by $300 \mathrm{~s}$ time steps in both the longitudinal and latitudinal directions; the temporal resolution was $30 \mathrm{~min}$, and the spatial grid resolution used a $0.1^{\circ}$ grid.

\subsection{CFOSAT Data}

The satellite named CFOSAT, which launched on 28 October 2018 and is a joint mission by CNSA and CNES, carries an advanced technological instrument, SWIM, designed to obtain simultaneous wind and wave spectra over global seas, especially during extreme weather conditions. The SWIM device is a real-aperture radar in the $\mathrm{Ku}$-band, resulting in convenient retrieval of wave spectra by analysis of the SWIM backscattering signals. The SWIM products (version 5.12) are generated using the latest processing chain issue from 25 April 2019 and are stored as three levels, i.e., Level-1A concerning the modulation spectrum, and Level-1B and Level-2 for the wind speed and wave spectra. The improvement of Level-2 SWIM products results from an upgrade of the modulation transfer function (MTF) that yielded strong reduction of bias for the wave parameter $H_{s}$ compared to model or buoy data. The directional wave spectra from off-nadir beam are derived from the Level-2 products of SWIM (version 5.1.2), which is proceeded by a new empirical speckle correction algorithm and no mask on the wave spectra. In particular, the directional wave spectrum 
was segmented into up to three partitions without smoothing through the frequencies and directions. The footprint of the CFOSAT satellite with the tracks of Typhoon Lekima (a) and SWIM-measured wave spectra (b) at 18:58 UTC on 25 April 2019 is illustrated in Figure 2. Note that the SWIM-measured wave spectrum has $180^{\circ}$ ambiguity; therefore, the true energy of the wave spectrum is half of the integral of the SWIM-measured wave spectrum. The parameters of the wave spectrum in the derivation of sea surface roughness, i.e., significant wave height $(\mathrm{SWH}) H_{s}$ and the dominant phase speed $c_{p}$, are calculated by

$$
\begin{gathered}
\mathrm{H}_{\mathrm{s}}=2 \sqrt{\int S_{k} d k}, \\
c_{p}=\left(\frac{g \lambda_{p}}{2 \pi}\right)^{\frac{1}{2}},
\end{gathered}
$$

where $S_{k}$ is a double-peaked wave spectrum in term of the wave number $k$; $g$ is the gravity acceleration; and $\lambda_{p}$ is the wave length at peaks in a wave spectrum. Those parameters were directly obtained from SWIM wave spectrum products during 20 typhoons in the last two-year mission, and the tracks are presented in Figure 3. As mentioned in [53], it is concluded that the RMSE of the SWIM-measured peak wave period and mean wave direction at a wavelength between $70 \mathrm{~m}$ and $500 \mathrm{~m}$ was $0.9 \mathrm{~s}$ and $20^{\circ}$, respectively. However, the accuracy of the SWIM-measured SWH was relatively higher $(\sim 0.6 \mathrm{~m})$ than the overall error $(\sim 0.5 \mathrm{~m})$. Moreover, more careful calibration is needed due to the underestimation of the energy of partitions.

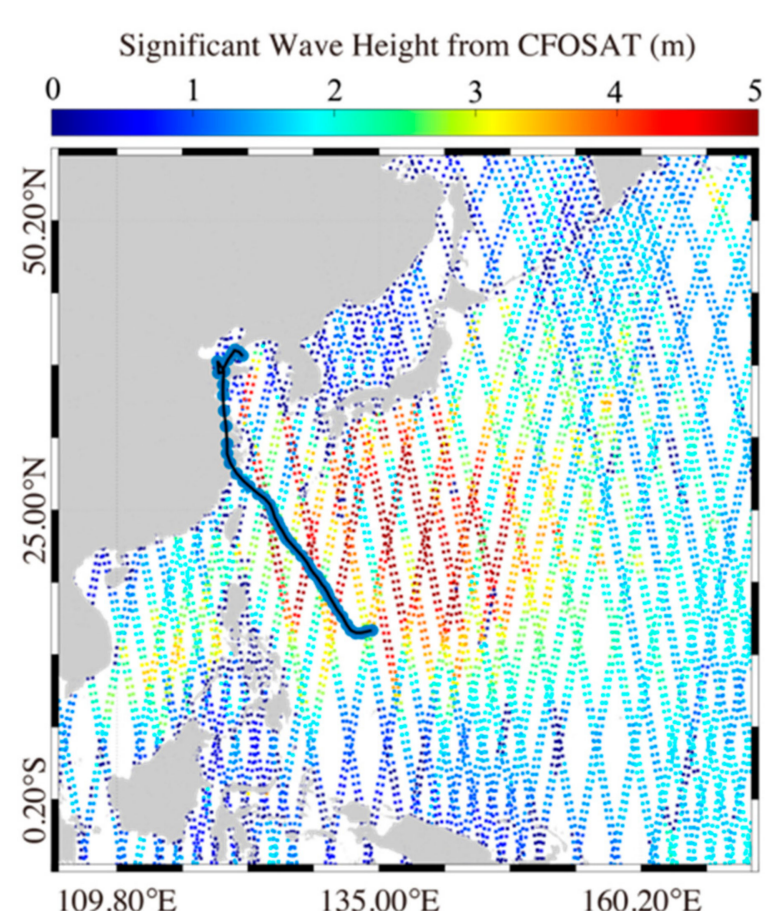

(a)

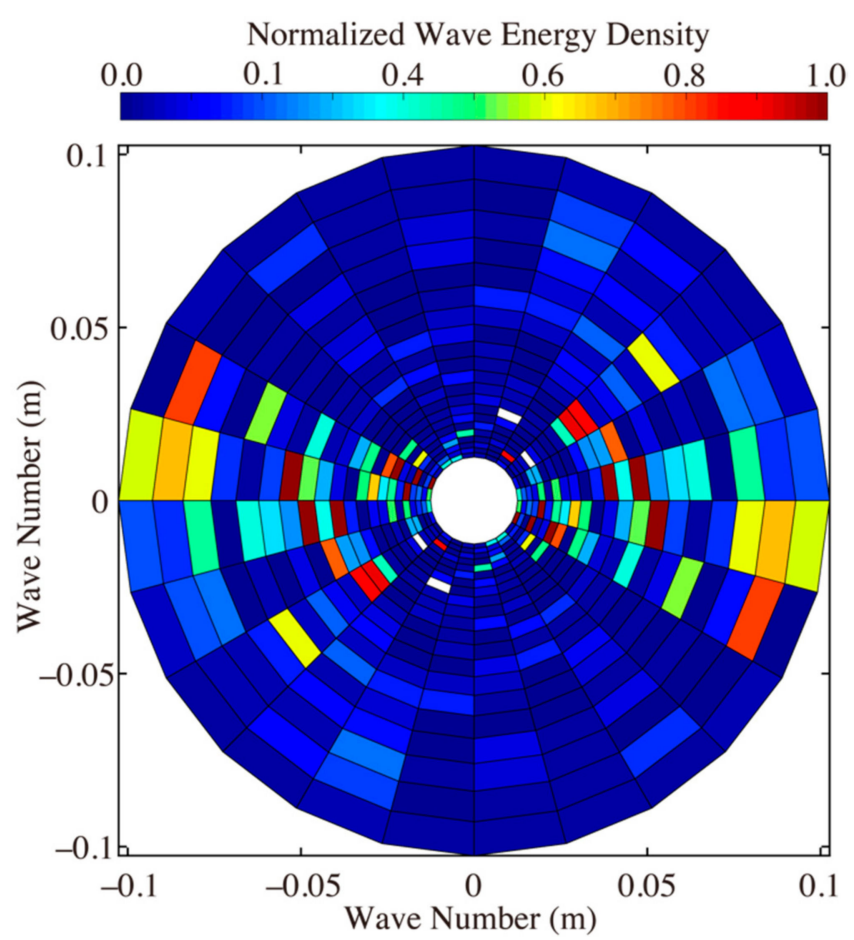

(b)

Figure 2. (a) The footprints of $H_{S}$ from Surface Wave Investigation and Monitoring (SWIM) onboard the Chinese-French Oceanography SATellite (CFOSAT) satellite with the tracks of Typhoon Lekima (2019). (b) The SWIM-measured wave spectrum at 18:58 UTC on 25 April 2019.

\subsection{Buoy Observations}

During the three typhoons, the $H_{S}$ data from in situ buoys were available, which were confidentially provided by North China Sea Marine Forecasting Center. The winds (speeds and directions) and waves (basically SWHs and dominant propagation directions) 
are measured by an SBY1-1 carrying anemometer and wave sensor moored on the $10 \mathrm{~m}$ diameter buoys, manufactured by the Institute of Oceanographic Instrumentation, Shandong Academy of Sciences (IOISAS). Typically, the accuracy of SWH is $\pm(0.1+5 \% \times \mathrm{SWH})$ with SWH up to $25 \mathrm{~m}$, and the accuracy of the wind speed is about $0.5 \mathrm{~m} / \mathrm{s}$ with a speed up to $25 \mathrm{~m} / \mathrm{s}$. Most the buoys were located at nearshore waters around Zhoushan Island, as the cyclone eyes of Typhoon Fung-wong (2014) and Typhoon Chan-hom (2015) passed the Zhoushan Islands, and the winds were simultaneously measured from the buoys during the two typhoons. The two buoys during Typhoon Lekima (2019) were located at the coastal waters in the Bohai Sea; however, the information on wind was not available for the two buoys. The SWHs from buoys were used to validate the WW3-simulated waves using an improved parameterization for the drag coefficient. The geographic locations of the buoys are listed in Table 1.

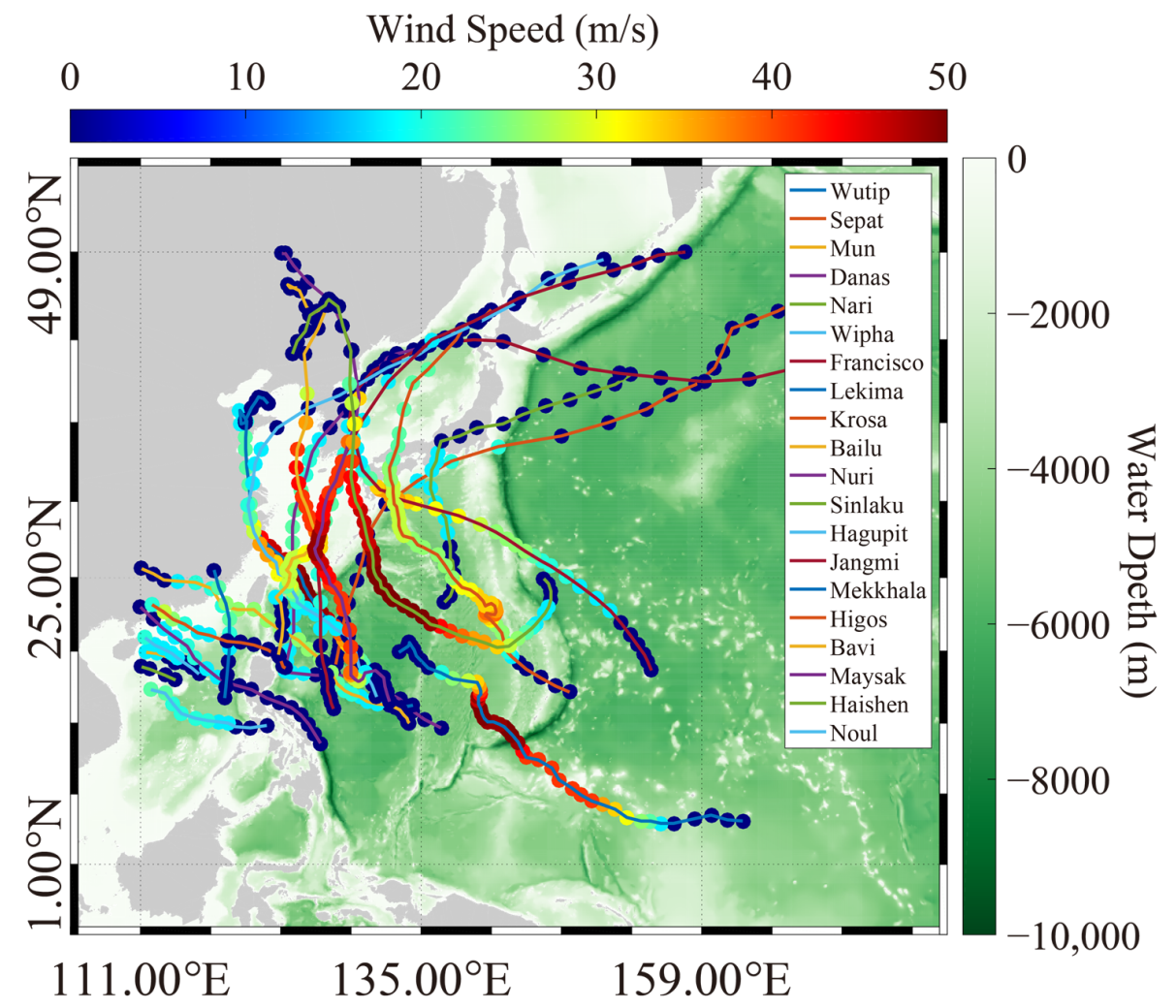

Figure 3. The tracks of 20 available typhoons with SWIM wind and wave products, overlaid by the water depth from the General Bathymetry Chart of the Oceans (GEBCO).

Table 1. The geographic locations of buoys in China Seas used in this study.

\begin{tabular}{ccccc}
\hline Typhoon ID & Time (MM-YY) & Longitude $\left({ }^{\circ} \mathbf{N}\right)$ & Latitude $\left({ }^{\circ} \mathbf{W}\right)$ & Water Depth $(\mathbf{m})$ \\
\hline \multirow{3}{*}{ Fung-wong } & 122.002 & 31.367 & 7.00 \\
& & 122.820 & 30.994 & 26.00 \\
& & 122.013 & 30.513 & 26.00 \\
& & 122.533 & 31.102 & 14.00 \\
Chan-hom & 122.745 & 29.750 & 39.00 \\
& \multirow{3}{*}{ July 2015 } & 122.002 & 31.367 & 7.00 \\
& & 122.548 & 30.503 & 8.00 \\
& & 122.013 & 30.513 & 14.00 \\
& & 122.533 & 31.102 & 44.00 \\
Lekima & 124.001 & 31.000 & 40.00 \\
\hline
\end{tabular}




\section{Methodology}

In this section, the principle of the WW3 model is described according to the wave energy propagation equations, and then the parameterization scheme for the drag coefficient is derived based on a well-known formula for sea surface roughness estimation [48].

\subsection{Description of the Wave Model}

At present, the typhoon waves are conveniently hindcasted from the WW3 model that allows realistic simulations of wave parameters for regional and global seas according to the forcing wind, bottom friction, and current conditions. This numerical model is a third-generation fully spectral model.

The basic principle of the WW3 model for simulating waves is to calculate the development of a sea state by solving the following wave propagation balance equation:

$$
\frac{N(k, \theta ; x, t)}{\sigma}=S_{i n}+S_{n l}+S_{d s}+S_{b o t}+S_{d b},
$$

in which the dimensional wave spectrum $N$ represents the variation of wave energy; $\sigma$ is the intrinsic frequency; $k$ is the wave number; $\theta$ is the wave propagation direction; $x$ and $t$ represent the space and time coordinates, e.g., the input term from winds $S_{i n}$, the triad and quadruplet wave-wave interaction term $S_{n l}$, the dissipation term by wave breaking $S_{d s}$ and the wave-bottom friction $S_{b o t}$. The descriptions of the parameterizations of these terms in detail are introduced in the technical manual for the WW3 model and are not repeated here.

The WW3 model offers optional parameterizations of physical processes for users depending on the requirements for various purposes, e.g., typhoons and ice-wave interactions. In particular, as for various purposes, the parameterizations can be user-defined according to the results of sensitivity experiments. Specifically, the reduction of the drag coefficient is essential for wave simulation in typhoons because intense wave breaking causes the collapse of wave steepness and wave age during high winds [54].

\subsection{Derivation of the Drag Coefficient}

A well-developed formula of sea surface roughness $z_{0}$ related to wind friction speed $u_{*}$ using the measurements recorded by buoys, towers, and ships is stated as follows [1]:

$$
\frac{g z_{0}}{u_{*}^{2}}=\alpha,
$$

where

$$
u_{*}=\sqrt{C_{d} U_{10}^{2}},
$$

in which, $g$ is the gravity coefficient, $C_{d}$ is the drag coefficient, and $\alpha$ is a constant [55] that depends on the various sea states and wind speeds $U_{10}$. The general bulk flux algorithm Coupled Ocean-Atmosphere Response Experiment (COARE) 3.0 [56] provides three optional roughness parameterizations: one only considers the surface wind friction velocity; the other two approaches depend on the sea states [57], i.e., wave height and steepness, wave length, and wave age.

In practice, the sea roughness $z_{0}$ is directly related to the drag coefficient $C_{d}$ of $10 \mathrm{~m}$ height using Equation (6) [58], which is used in the WW3 and SWAN models. Although it is difficult to obtain sufficient data including wind and wave observations from moored buoys in typhoons, the wind and wave spectra simultaneously measured from SWIM onboard CFOSAT for 20 typhoons during the two-year mission were available for our work. In practice, the dataset is a valuable resource for adopting the parameterization for the drag coefficient $C_{d}$ of $10 \mathrm{~m}$ height at a high state once knowing sea roughness $z_{0}$.

$$
C_{d}=\left[\frac{0.4}{\ln \left(10 / z_{0}\right)}\right]^{2},
$$


The comprehensive analysis concluded that wave steepness $\delta$ and wave age $\beta$ denoting the representability of wave growth are two parameters directly related to sea roughness $z_{0}$ [55]. Furthermore, Equation (7) of sea roughness $z_{0}$ considering the dependence of wind and wave states is stated as

$$
z_{0}=229.2 \delta^{4.5} \beta^{1.56} U_{10}^{2} / g
$$

where

$$
\begin{gathered}
\beta=\frac{c_{p}}{U_{10}}, \\
\delta=\frac{H_{s}}{\lambda_{p}},
\end{gathered}
$$

where $U_{10}$ is the sea surface wind speed at $10 \mathrm{~m}$ above sea surface; $H_{s}$ is the $\mathrm{SWH}$, and $c_{p}$ is the dominant phase speed calculated from the wavelength at the spectral peak $\lambda_{p}$, as described in Equation (2).

As concluded in [55], the calculation of sea roughness $z_{0}$ considering dependence on wave states is more reliable than that derived without the term for waves. The key aspect of the derivation of the drag coefficient $C_{d}$ is the calculation of sea roughness $z_{0}$; therefore, the relation between sea roughness $z_{0}$ and two variables, i.e., wave steepness $\delta$ and wave age $\beta$, which are derived from SWIM wave products for 20 typhoons is presented in Figure 4 . The sea roughness $z_{0}$ is positively related to wave steepness $\delta$ and negatively related to wave age $\beta$, consistent with the findings in [55]. The accuracy of the sea roughness $z_{0}$ could improve the applicability of the parameterization for the drag coefficient.

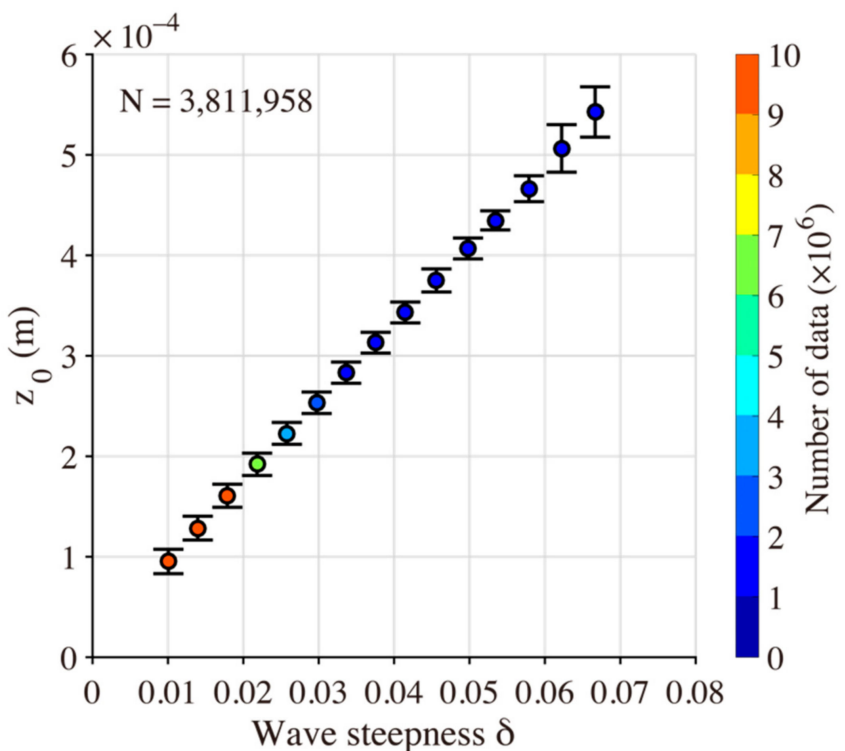

(a)

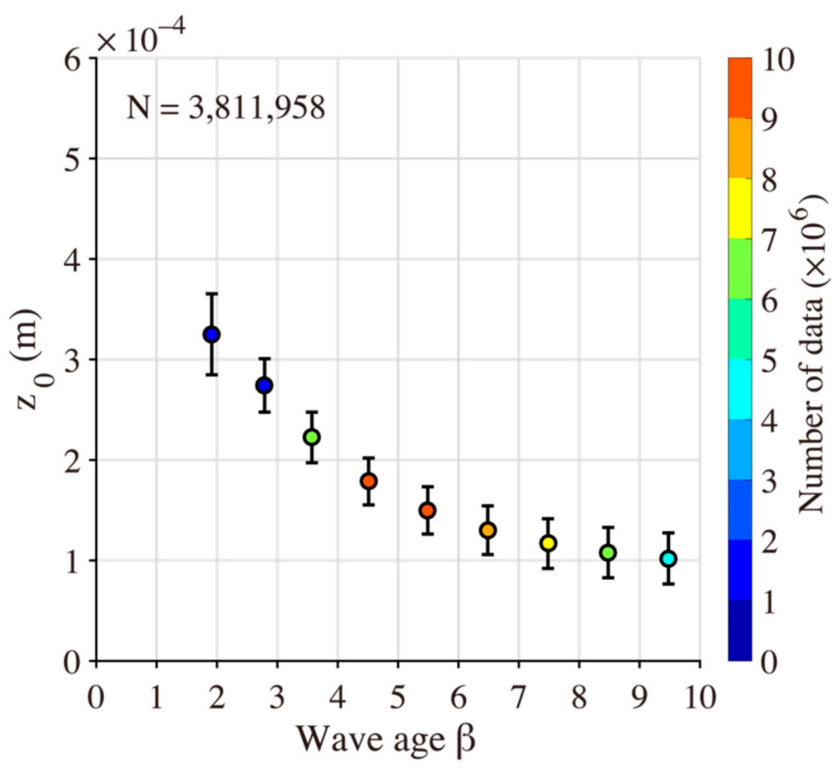

(b)

Figure 4. (a) The relation between sea roughness $z_{0}$ and wave steepness $\delta$ for a 0.004 bin. (b) The relation between sea roughness $z_{0}$ and wave age $\beta$ for a 0.1 bin.

However, the drag coefficient $C_{d}$ derived from the above equations is difficult to implement in the numerical model due to sea roughness $z_{0}$ also relying on the stability of the air-sea layer. According to the formula for the drag coefficient in the WW3 model, Equation (10) is applied in practice in the modelling process as employing the input/dissipation source terms, depending on the wind speed:

$$
C_{d} \times 10^{4}=A+B U_{10}+C U_{10}^{2}
$$

where the constants $A-C$ are fitted based on a combination of laboratory and field data. Several studies $[2,58]$ have proposed the fitted results of Equation (8) based on limited 
datasets; these are listed in Table 2. Note that the parameterization developed in [59] is treated as the default setting in the WW3 model. The derivation of constants $A-C$ at extreme sea states is further adopted to improve the accuracy of wave simulation during typhoons. The coefficient of determination $\left(R^{2}\right)$ in Table 2 is as shown in Equation (11). The variables $M$ and $N$ represent the observations of the drag coefficient considering the dependence of wind and wave states, which will be discussed in the later section, and the simulations taking the various values of constants $A-C$ in Equation (10), respectively. The flowchart is illustrated in Figure 5.

$$
\mathrm{R}^{2}=1-\frac{\left[\sum_{\mathrm{i}=1}^{\mathrm{n}}\left(\mathrm{M}_{\mathrm{i}}-\overline{\mathrm{M}}\right)(\mathrm{N}-\overline{\mathrm{N}})\right]^{2}}{\sum_{\mathrm{i}=1}^{\mathrm{n}}\left(\mathrm{M}_{\mathrm{i}}-\mathrm{M}\right)^{2} \sum_{\mathrm{i}=1}^{\mathrm{n}}\left(\mathrm{N}_{\mathrm{i}}-\overline{\mathrm{N}}\right)^{2}},
$$

Table 2. The values of constants $A-C$ in Equation (10) using Chinese-French Oceanography SATellite (CFOSAT) wind speeds and calculated sea roughness by Equations (8) and (9) using CFOSATmeasured winds and waves.

\begin{tabular}{ccccc}
\hline & A & B & C & $\begin{array}{c}\text { Coefficient of } \\
\text { Determination }\left(\mathbf{R}^{2}\right)\end{array}$ \\
\hline Oost et al. 2002 [2] & 2.5 & 1.3 & -0.24 & 0.93 \\
Taylor and Yelland, 2001 [57] & 47 & -7.2 & 0.33 & 0.88 \\
Hwang, 2011 [59] & 8.058 & 0.967 & -0.016 & 0.93 \\
this study & 7.2 & 0.27 & 0.056 & 0.97 \\
\hline
\end{tabular}

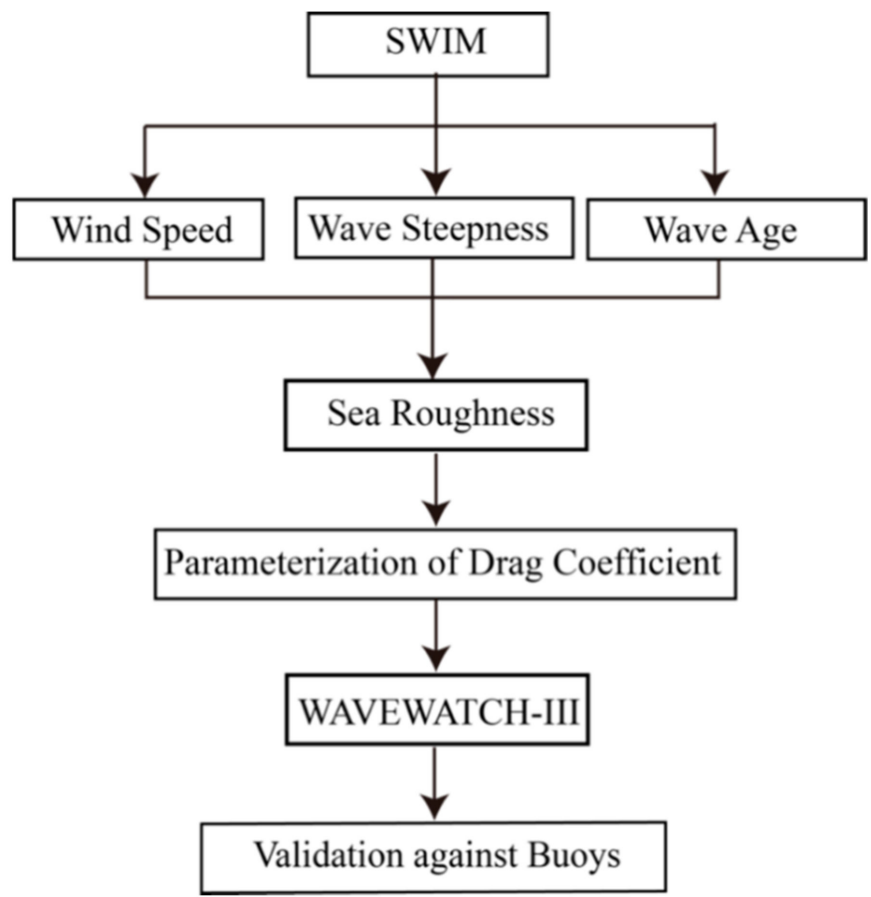

Figure 5. The flowchart of methodology in this study.

The experimental data from the southern North Sea at the research platform Meetpost Noordwijk (MPN) were employed for the parameterization of the drag coefficient [2], as well as in [57], utilizing the data at $18 \mathrm{~m}$ water depth, based on the remote-sensing data and the parameterization refitted in [59] with the winds below about $15 \mathrm{~m} / \mathrm{s}$. Compared with the above data, the wind from the data collection in this study reached $30 \mathrm{~m} / \mathrm{s}$, resulting in a high correlation $\left(R^{2}=0.97\right)$ between the observations and simulations. 


\subsection{Error Metrics}

To analyze the simulation quality, three error metrics, i.e., RMSE, scatter index (SI), and Bias, were calculated by matching the WW3-simulated $H_{s}$ with the measurements from moored buoys, as stated in Equations (10)-(14):

$$
\begin{gathered}
\text { RMSE }=\sqrt{\frac{1}{n} \sum_{i=1}^{n}\left(S_{i}-B_{i}\right)^{2}}, \\
\mathrm{SI}=\frac{1}{\bar{B}} \sqrt{\frac{1}{n} \sum_{i=1}^{n}\left[\left(S_{i}-\bar{S}\right)-\left(B_{i}-\bar{B}\right)\right]^{2}}, \\
\text { Bias }=\frac{1}{n} \sum_{i=1}^{n}\left(S_{i}-B_{i}\right),
\end{gathered}
$$

where $B_{i}$ is the observation data from each buoy and $i$ represents the measurement number; $S_{i}$ represents the simulations from the WW3 model covering the geographic locations of buoy stations, and $\bar{S}$ and $\bar{B}$ are the mean values of $B_{i}$ and $S_{i}$, respectively.

\section{Results}

The fitted results using the new parameterization of the drag coefficient derived from sea surface roughness is first presented and compared with the results of three other parameterizations. The four parameterizations were implemented in the WW3 model, and the simulated $H_{s}$ was validated against the collocated measurements from moored buoys during Typhoons Fung-wong (2014), Chan-hom (2015), and Lekima (2019). In the validation dataset, the spatial distance between the WW3 grids and available buoys was within $3 \mathrm{~km}$, and time difference was less than $15 \mathrm{~min}$. Finally, the spatial variation of WW3-simulated $H_{s}$ between the new parameterization and existing parameterizations is discussed.

\subsection{Refitted Results}

The collocated datasets, including the drag coefficient $C_{d}$ derived from sea roughness $z_{0}$ and SWIM-measured wind speeds $U_{10}$, were used for re-tuning the coefficients $A-C$ in Equation (10) by a linear regression method. Figure 6 shows the fitted result (black solid line) for three other parameterizations, including those proposed in [2] (blue cross), [57] (gray five-pointed star), and [59] (green dashed line), in which the error bars represent the standard deviations of drag coefficient $C_{d}$ for a $1 \mathrm{~m} / \mathrm{s}$ bin of wind speed $U_{10}$ up to $50 \mathrm{~m} / \mathrm{s}$. The results showed that the adopted parameterization in this study best fit the collocated data, especially at moderate-to-high wind speeds $(>12 \mathrm{~m} / \mathrm{s})$. However, with increasing wind speeds $(>30 \mathrm{~m} / \mathrm{s})$, the drag coefficient $C_{d}$ continued to increase due to the lack of collocated data at higher winds. This behavior is different from the basic principle that the drag coefficient $C_{d}$ should decrease at extreme strong winds, as revealed based on a laboratory experiment.

As an example, Figure 7a shows the case of the drag coefficient $C_{d}$ map using the re-fitted values in Equation (10). Note that the wind speeds are derived from a $0.1^{\circ}$ gridded composite wind field of Typhoon Lekima (2019) at 20:30 UTC on 1 October 2019. The high drag coefficient $C_{d}$ was located on the right-side of the typhoon eye, caused by the strong winds, as shown in Figure $7 \mathrm{~b}$. As stated in [60], the variation of drag coefficient $C_{d}$ is affected by the sea state caused by wind-swell interactions. Moreover, based on a laboratory experiment, the aerodynamic drag in typhoons is also affected by the contribution of the spray from wave breaking [61]. This is the probable explanation as to why the drag coefficient $C_{d}$ has a saturation tendency at high winds. Although the sea roughness $z_{0}$ in the parametrization of the drag coefficient includes the wave term in this study, the wave simulation in the typhoon eye still encounters difficulty because the swell dominates and because of huge wave breaking in such a region. Collectively, although the proposed parameterization is specifically adopted by remote-sensed wave spectrum data, it has limitations at extreme winds due to no available data under such conditions. 


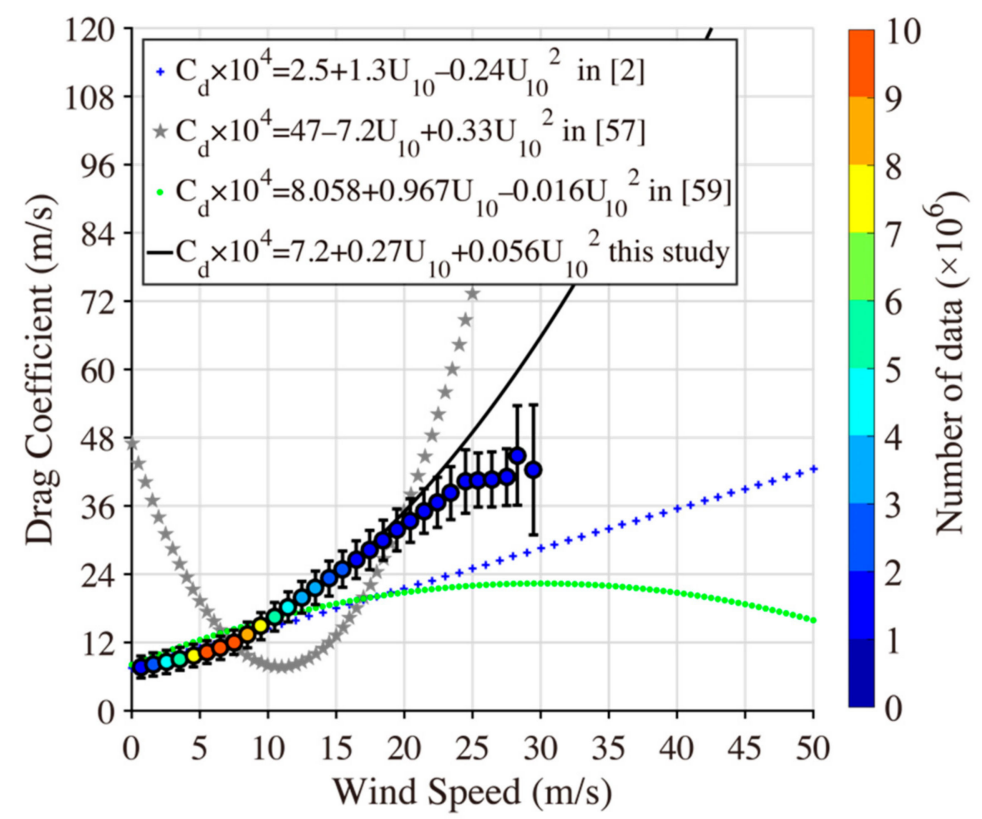

Figure 6. The fitted results based on Equation (4) using values listed in Table 2 versus SWIMmeasured wind speeds in 20 typhoons. The error bars represent the standard deviations of drag coefficient $C_{d}$ for a $1 \mathrm{~m} / \mathrm{s}$ bin of wind speed $U_{10}$ up to $50 \mathrm{~m} / \mathrm{s}$. The relations between drag coefficient $C_{d}$ and wind speed $U_{10}$ for three existing models adapted from [2] (blue cross), [57] (gray five-pointed star), and [59] (green dashed line), as well as the current model (black solid line).

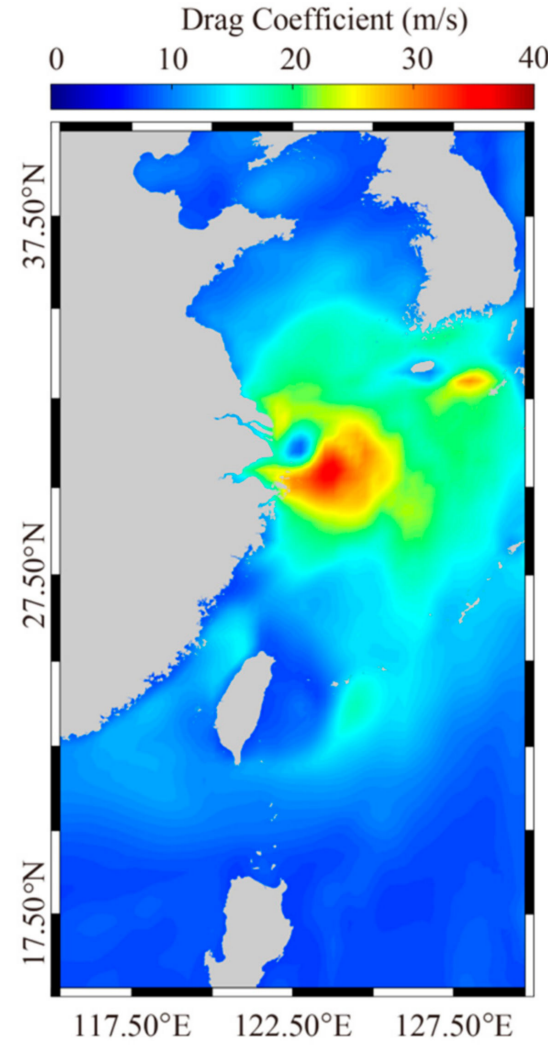

(a)

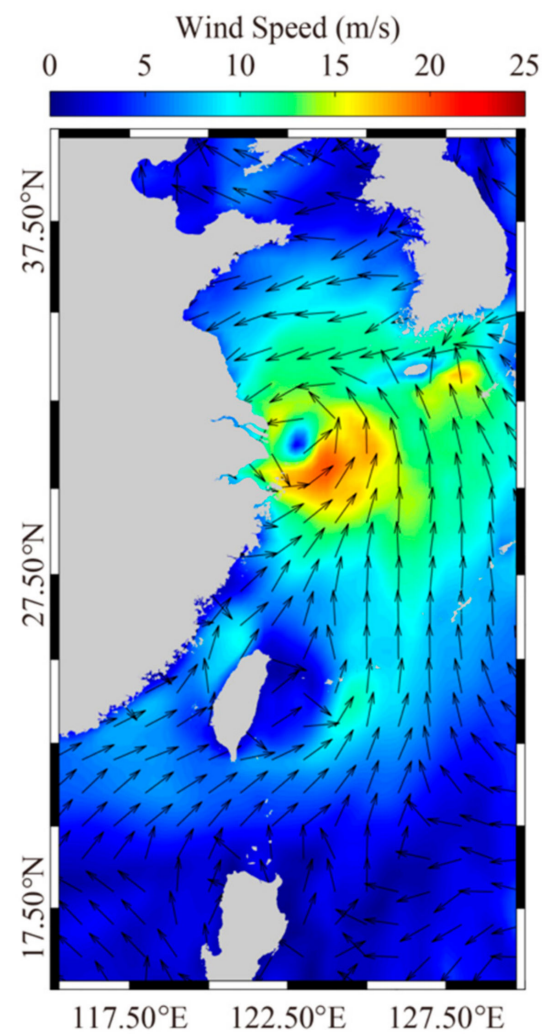

(b)

Figure 7. (a) The case of the drag coefficient $C_{d}$ map using the refitted values in Equation (7). (b) The wind speeds were derived from the $0.1^{\circ}$ gridded composite wind field at 20:30 UTC on 1 October 2019. 


\subsection{Validation of WW3-Simulated $H_{s}$}

The comparisons of the WW3-simulated $H_{s}$ using the models in [2] (blue line), [57] (gray line), [59] (green line), and this study (red line) with the measurements from the buoy station $\left(122.745^{\circ} \mathrm{W}, 29.750^{\circ} \mathrm{N}\right)$ marked by black spots on September during Typhoon Fungwong (2014) are shown in Figure 8. In this case, the maximum $H_{s}$ is about $6 \mathrm{~m}$. Although the tendency of simulations using the four models are generally consistent with the measured data from the buoy station, the model described herein had the best performance at moderate sea states $\left(H_{S}>4 \mathrm{~m}\right)$, avoiding the underestimation seen in employing the parameterization in [52]. The maximum $H_{S}$ reached more than $9 \mathrm{~m}$, measured by the buoy station $\left(122.745^{\circ} \mathrm{W}, 29.750^{\circ} \mathrm{N}\right)$ on July during Typhoon Chan-hom (2015). Figure 9 presents the comparisons of the WW3-simulated $H_{s}$ using the models in [2] (blue line), [57] (gray line), [59] (green line), and this study (red line). Again, it is clear that the accuracy of the WW3-simulated $H_{S}$ is significantly improved when employing the parameterization derived in this study, especially at extreme sea states.

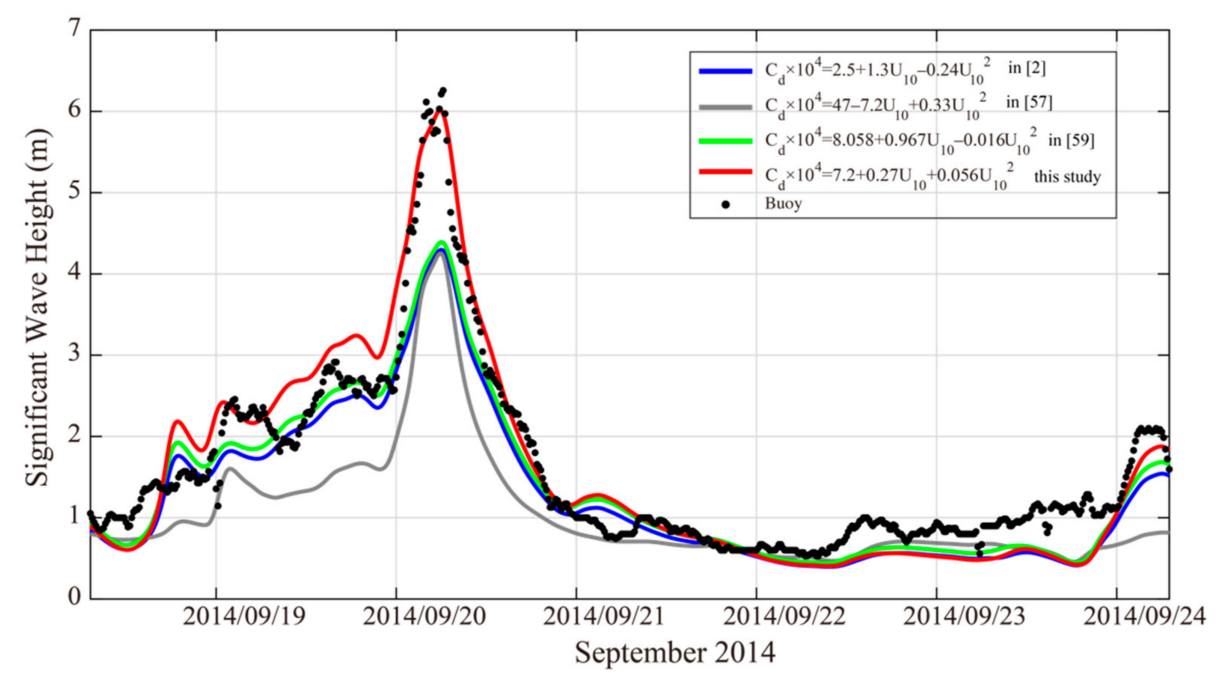

Figure 8. The comparisons of the WW3-simulated $H_{s}$ using the models adapted from [2] (blue line), [57] (gray line), [59] (green line), and this study (red line) with the measurements from the buoy station $\left(122.745^{\circ} \mathrm{W}, 29.750^{\circ} \mathrm{N}\right)$ on September during Typhoon Fung-wong (2014).

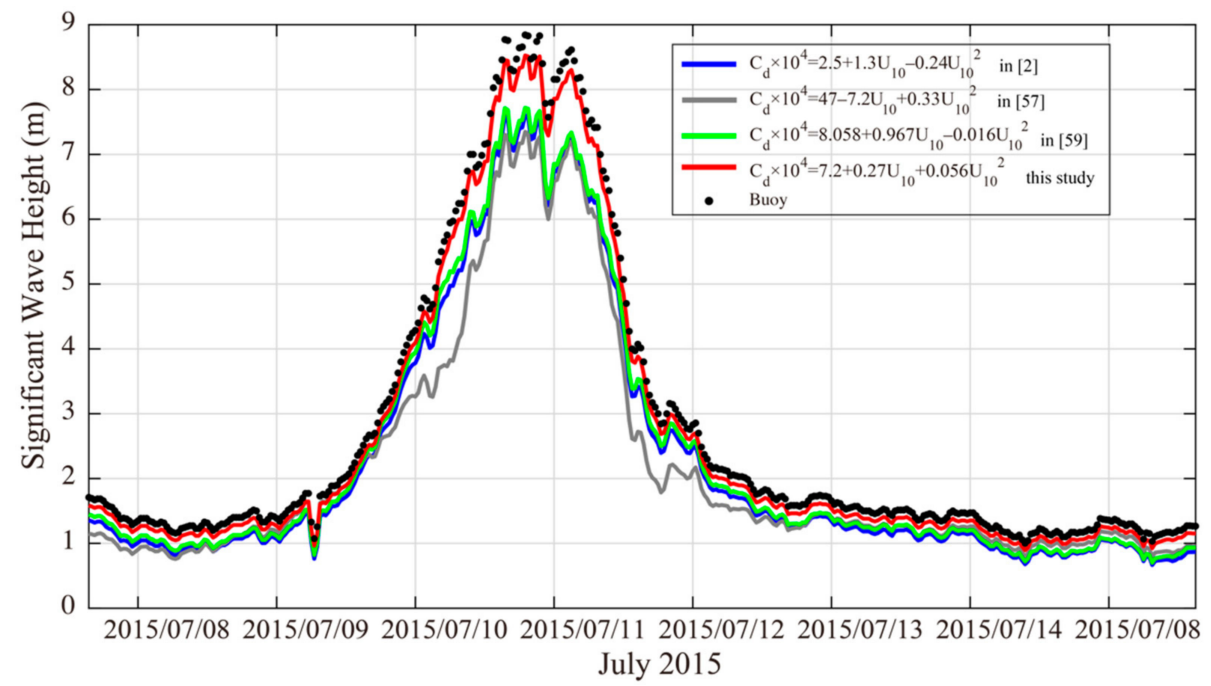

Figure 9. The comparisons of the WW3-simulated $H_{s}$ using the models adapted from in [2] (blue line), [57] (gray line), [59] (green line), and this study (red line) with the measurements from the buoy station $\left(122.745^{\circ} \mathrm{W}, 29.750^{\circ} \mathrm{N}\right)$ in July during Typhoon Chan-hom (2015). 
The statistical analysis of WW3-simulated $H_{S}$ compared with the measurements from all available buoys is presented in Figure 10. Because there are no available measurements of the mean wave period from collected buoys, a comparison of the mean wave period is not done here. In total, more than 5000 match-ups with moored buoys during the three typhoons were obtained. This data collection was used for the statistical analysis of WW3simulated $H_{S}$ by four parameterizations for the drag coefficient. The results indicate a $0.49 \mathrm{~m}$ RMSE with a 0.35 SI (Figure 10d), less than the $0.55 \mathrm{~m}$ RMSE of $H_{s}$ with $>0.4$ SI from the WW3 model using the other three existing parameterizations (Figure $10 \mathrm{a}-\mathrm{c}$ ). In this sense, the proposed parameterization for the drag coefficient is recommended for use in typhoon wave simulations by the WW3 model, especially for extreme sea states.

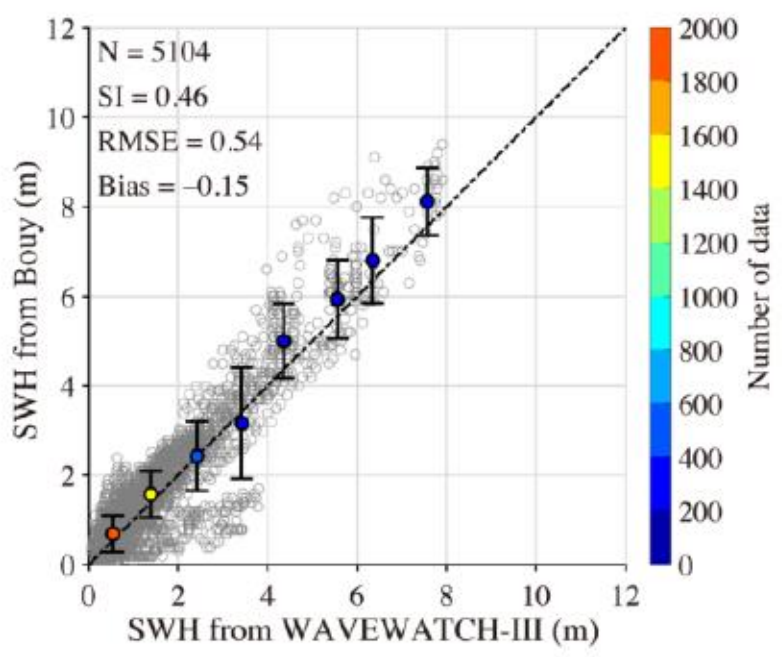

(a)

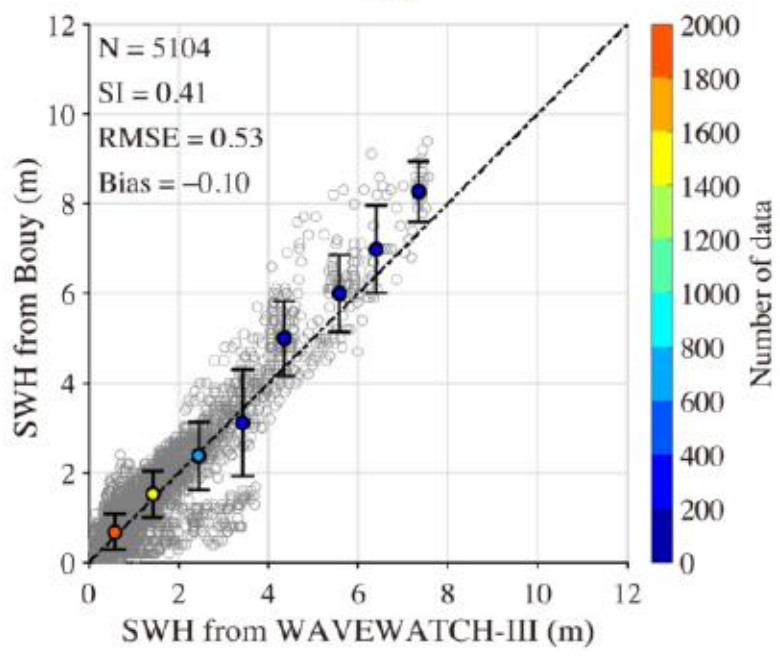

(c)

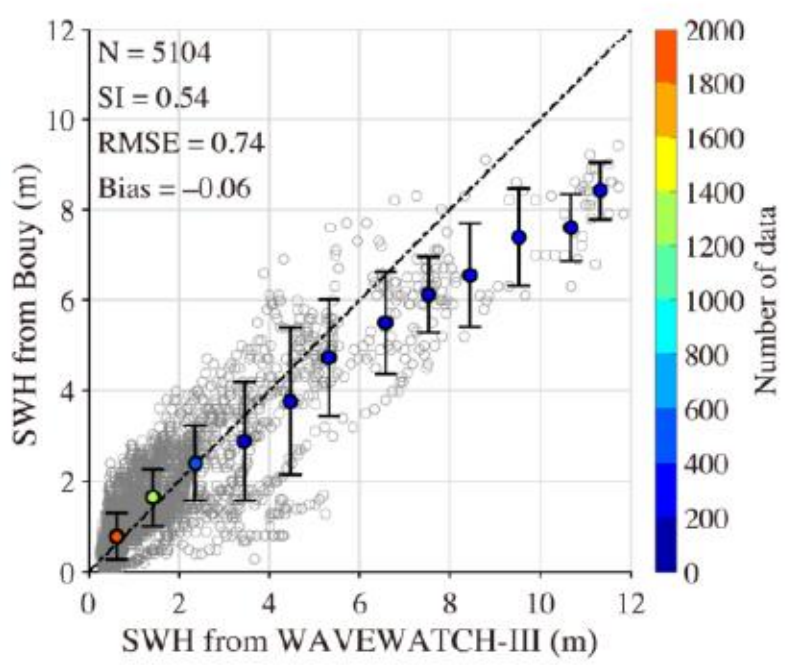

(b)

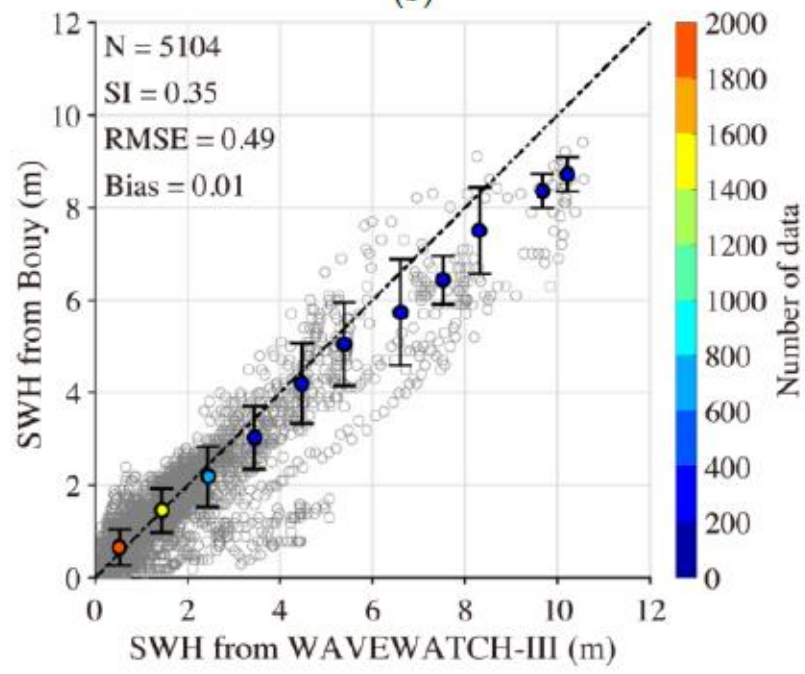

(d)

Figure 10. The statistical analysis of WW3-simulated $H_{s}$ compared with the measurements from all available buoys using parameterizations adapted from in [2] (a), [57] (b), [59] (c), and this study (d), in which the error bars represent the standard deviations for a $1 \mathrm{~m}$ bin of $H_{s}$ up to about $10 \mathrm{~m}$.

\subsection{Discussion}

The applicability of the four parameterizations for the drag coefficient at various sea states was analyzed. The bias (buoy-measured minus WW3-simulated $H_{s}$ ) versus $H_{S}$ from moored buoys is shown in Figure 11, in which a bin size of $1 \mathrm{~m}$ for $H_{S}$ was used to group the data pairs, and the error bars represent the standard deviations of each bin. Generally, the bias range was $\pm 1 \mathrm{~m}$; however, the relation between the variation of bias 
increased at low-to-moderate sea states ( $3 \mathrm{~m}<H_{s}<7 \mathrm{~m}$ ). The variation of bias remained at about $0.5 \mathrm{~m}$ at $H_{s}$ greater than $3 \mathrm{~m}$ for the parameterizations in [57] (Figure 11b) and [59] (Figure 12c), as shown in Figure 11d using the parameterization proposed in this study, indicating that various sea states had little impact on bias with increasing $H_{s}$ up to $7 \mathrm{~m}$. As for parameterizations in [2] (Figure 11a), the variation oscillated with $H_{s}$ increasing above $3 \mathrm{~m}$. The accuracy of WW3-simulated $H_{s}$ using the proposed parameterization should be improved at the sea states with $H_{s}<7 \mathrm{~m}$.

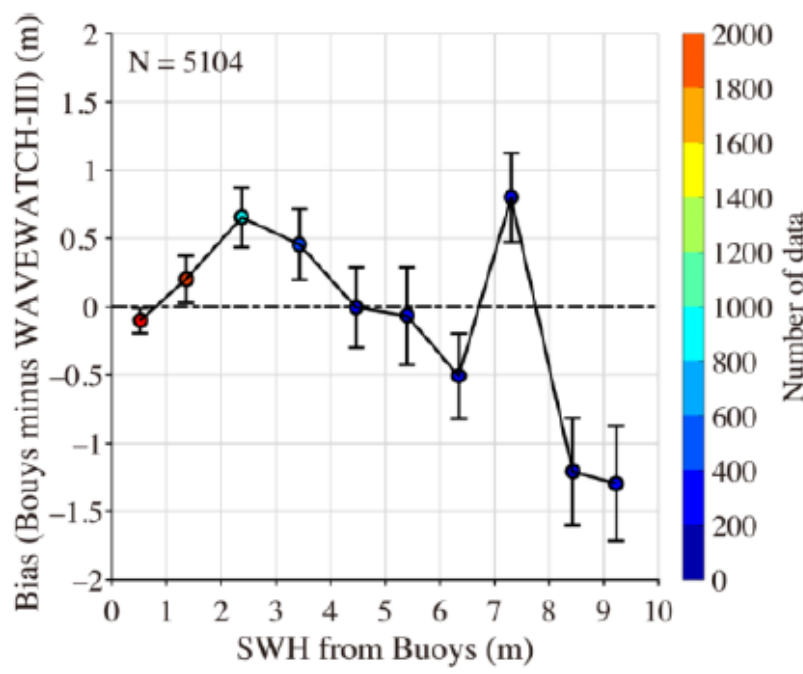

(a)

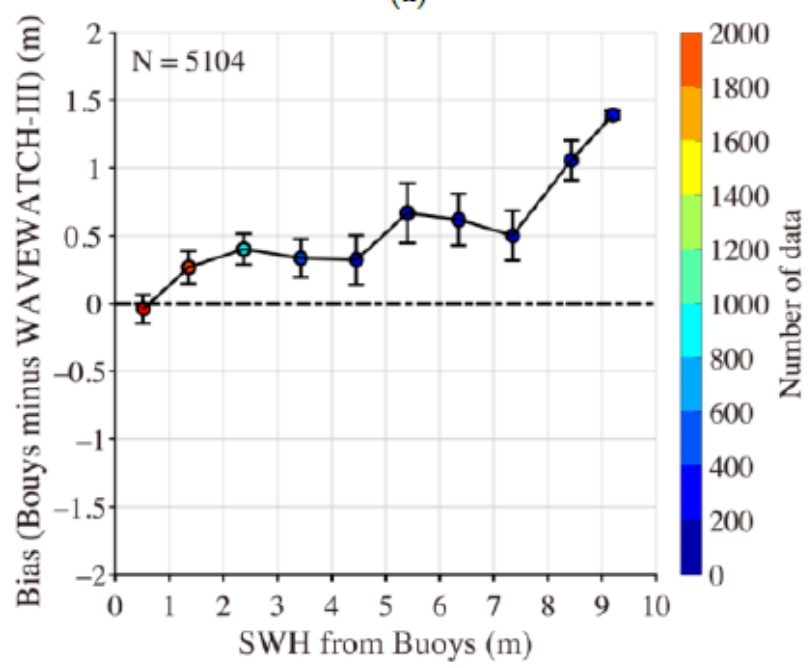

(c)

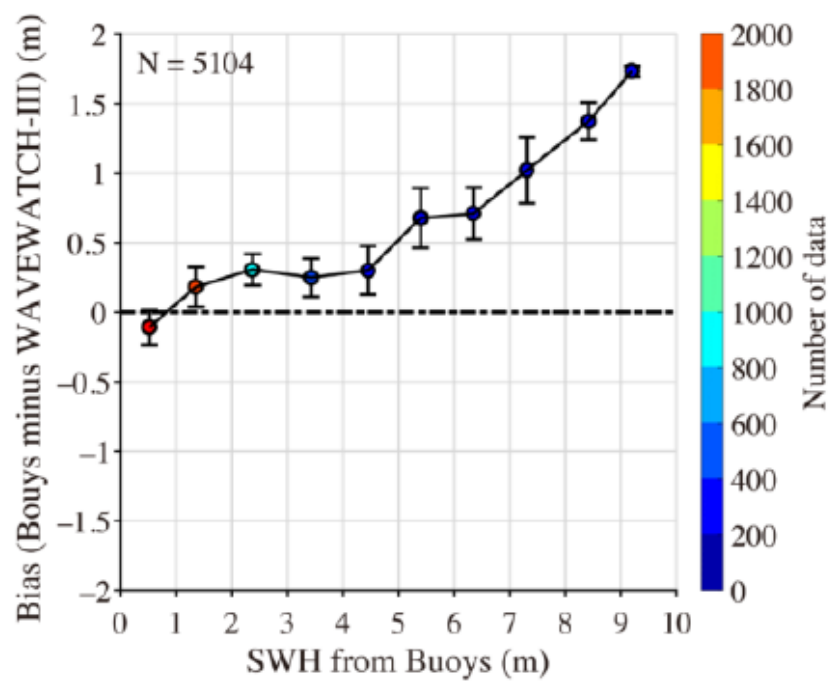

(b)

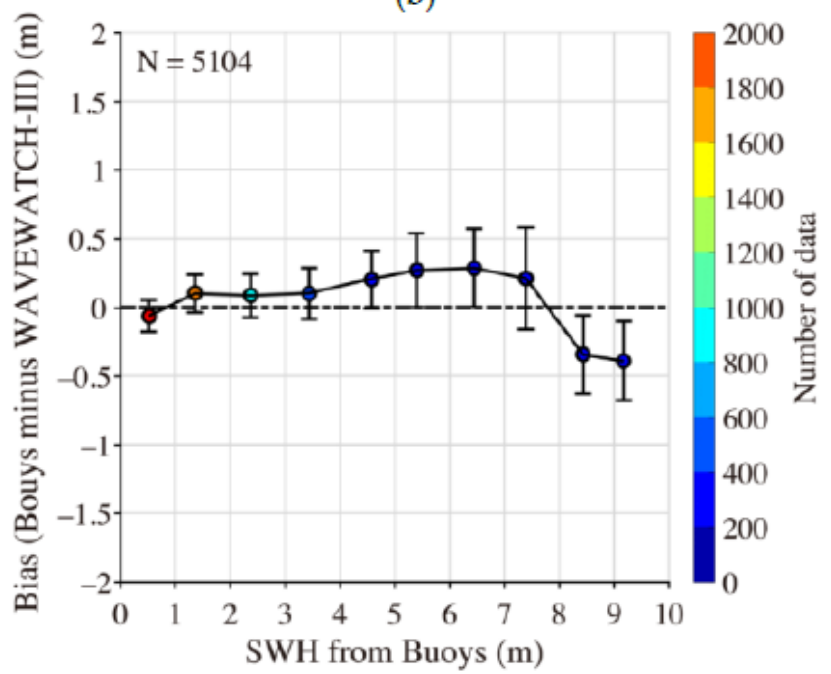

(d)

Figure 11. The statistical analysis of bias (buoys minus WW3-simulated $H_{s}$ ) compared with the measurements from all available buoys using the parameterizations adapted from [2] (a), [57] (b), [59] (c), and this study (d), in which the error bars represent the standard deviation for a $1 \mathrm{~m}$ bin of $\mathrm{H}_{\mathrm{s}}$ up to about $10 \mathrm{~m}$.

Similarly, the bias (buoy-measured minus WW3-simulated $H_{s}$ ) versus the wind speeds from composited H-E winds is shown in Figure 12, in which a bin size of $1 \mathrm{~m} / \mathrm{s}$ for wind speed was used to group the data pairs, and the error bars represent the standard deviations of each bin. As for the existing three parameterizations, the bias reached $2 \mathrm{~m}$ (Figure 12a-c) and increased with increasing winds. Moreover, the variation of bias remained at $\sim 0.5 \mathrm{~m}$ of $H_{s}$ (Figure 12d) using the parameterization proposed in this study. Again, the analysis results show that the adopted parameterization enhanced the applicability of the WW3 model for typhoon wave forecast, as the error of simulation will not increase with growing winds and sea states. 


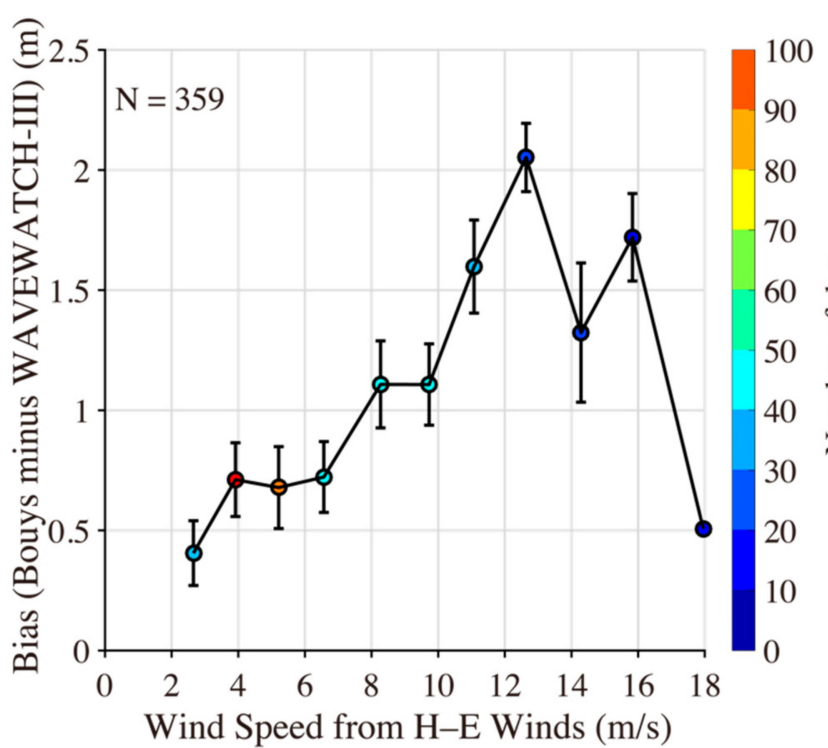

(a)

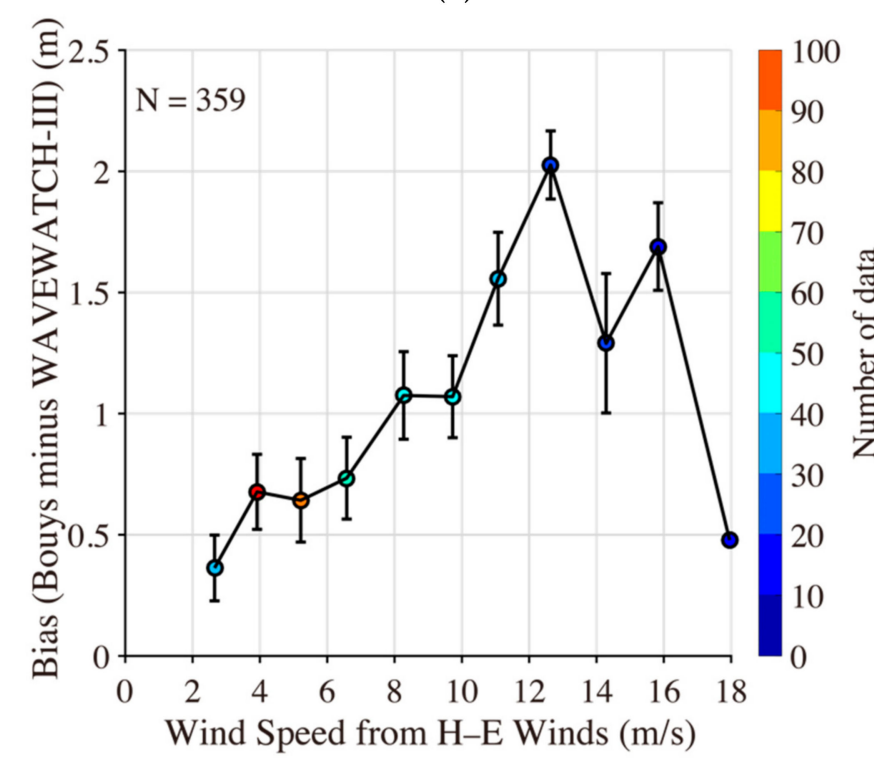

(c)

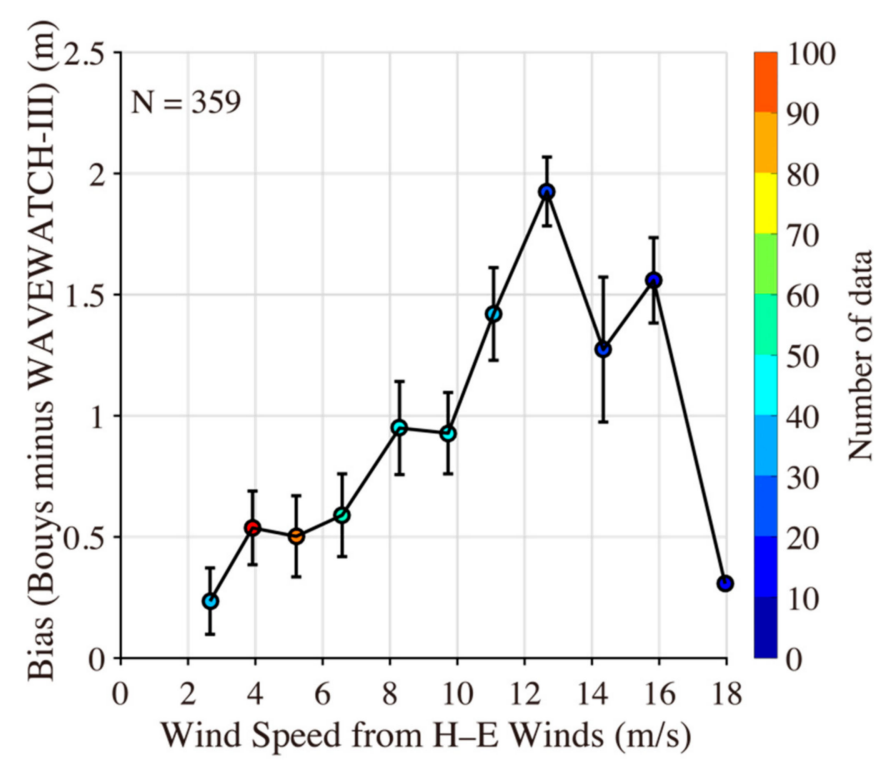

(b)

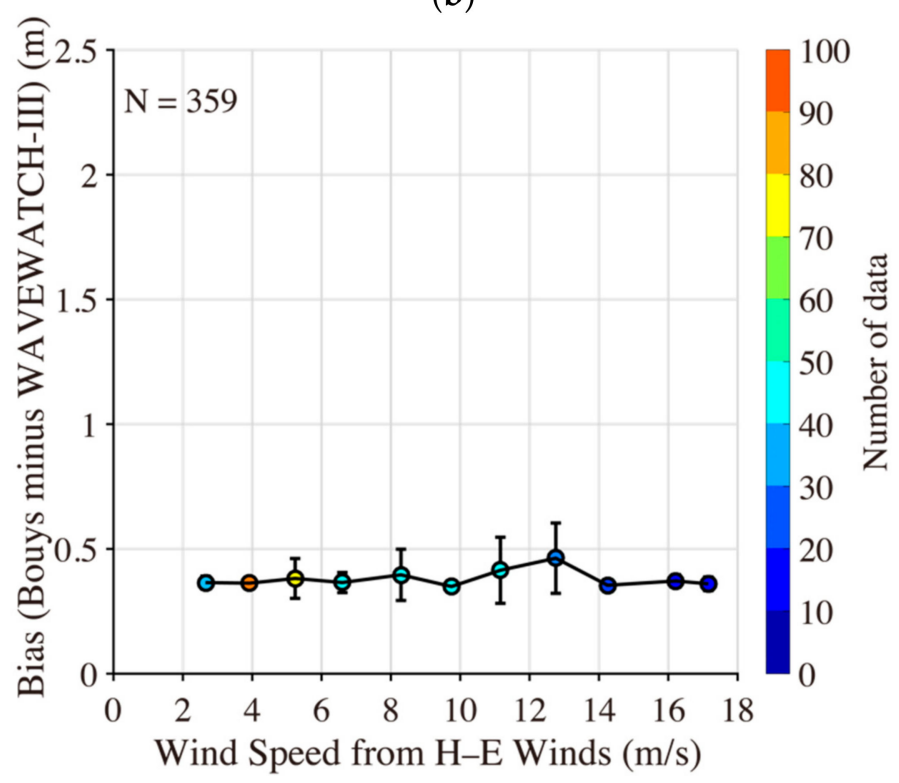

(d)

Figure 12. The statistical analysis of bias (buoys minus WW3-simulated $H_{s}$ ) compared with the wind speeds from composited H-E winds using the parameterizations in [2] (a), [57] (b), [59] (c), and this study (d), in which the error bars represent the standard deviation for a $1 \mathrm{~m}$ bin of $H_{s}$ up to about $10 \mathrm{~m}$.

\section{Conclusions}

The parameterization of the drag coefficient $C_{d}$ can improve the accuracy of wave simulations from a numerical wave model, especially at extreme sea states. However, owing to the danger in tropical cyclones resulting in few available data, it is difficult to enhance the applicability of parameterizations of the drag coefficient $C_{d}$ in tropical cyclones. With the development of remote-sensing techniques, the observations at high sea states are valuable resources for oceanographic research. In particular, SWIM onboard CFOSAT can simultaneously provide information on the wind and wave spectra. In this sense, the parameterization of the drag coefficient $C_{d}$ could be adopted based on the collocated wind and wave observations in tropical cyclones. In particular, the parameterization of the drag coefficient in the WW3 model can be conveniently modified by investigators.

In this work, the SWIM products available for 20 typhoons in the last two-year mission were collected. The calculation of sea surface roughness $z_{0}$ was necessary to derive the 
parameterization of the drag coefficient $C_{d}$. The model considering the effects of wave steepness $\delta$ and wave age $\beta$ [55] was employed; this information could be obtained from SWIM wind and wave spectra. The refitted results of the parameterizations indicated that the proposed model performed better than the other three existing models, especially at wind speeds $U_{10}$ greater than $12 \mathrm{~m} / \mathrm{s}$. In practice, the adopted parameterization and other three existing parameterizations have been implemented in the switch ST2 package of the WW3 model for simulating the waves in typhoons. The forcing wind field is essential for wave simulations by a numerical model in tropical cyclones. It was found that the composited winds [61] had good performance for hurricane-generated wave simulation [62], e.g., combining Hurricane Research Division Wind Analysis System data with NCEP. In this study, cyclone wind fields [63] were generated by a Holland model [47] with the shape parameter equal to 0.4 [23]. Then, the composited wind fields were reconstructed based on the winds produced by the Holland model and ERA- 5 winds, named "H-E winds".

The WW3-simulated $H_{s}$ during three typhoons, i.e., Typhoons Fung-wong (2014), Chan-hom (2015), and Lekima (2019), was validated against the measurements from serval buoys. The time series of $H_{s}$ from two buoy stations yielded the result that WW3-simulated $H_{S}$ using the proposed parameterization was the most consistent with the observations. The results of the statistical analysis showed that the RMSE of $H_{s}$ was 0.49 with a $0.35 \mathrm{SI}$, less than the $0.55 \mathrm{~m}$ RMSE of $H_{s}$ with $>0.4$ SI using the other three existing parameterizations. Therefore, it is concluded that the proposed parameterization for the drag coefficient $C_{d}$ is suitable for wave simulation by the WW3 model during typhoons. This finding also resulted from analysis of the variation of bias (WW3-simulated $H_{s}$ minus buoy-measured $H_{s}$ ) at the various winds and sea states with $H_{s}<7 \mathrm{~m}$. In conclusion, the accuracy of simulated waves did not decrease with growing winds and sea states using the proposed parameterization. However, it is noted that the proposed parameterization must be adopted at high winds $(>30 \mathrm{~m} / \mathrm{s})$.

The sea fetch has been expanded due to the reduction of sea ice, resulting in the increasing effects induced by waves in the Arctic Ocean [64]. As a matter of fact, the drag coefficient in the presence of sea ice floats differs from that under normal conditions. In the future, the accuracy of WW3-simulated waves will be improved by enhancing the applicability of the parameterization for the drag coefficient $C_{d}$ in the Arctic and Antarctic oceans.

Author Contributions: Conceptualization, W.S. and T.J., methodology, W.S. and W.W.; validation, W.S. and T.J.; formal analysis, W.S. and Y.Z.; investigation, W.S. and J.S.; resources, W.S.; writingoriginal draft preparation, W.S. and J.S.; writing-review and editing, Y.Z., J.S. and W.W.; visualization, W.S. and W.W.; funding acquisition, W.S. and W.W. All authors have read and agreed to the published version of the manuscript.

Funding: This research was funded by the National Key Research and Development Program of China under contract nos. 2016YFC1401100 and 2017YFA0604904, the National Natural Science Foundation of China under contract nos. 41806005 and 42076238, and the Shanghai Frontiers Research Center of the Hadal Biosphere.

Institutional Review Board Statement: Not applicable.

Informed Consent Statement: Not applicable.

Data Availability Statement: Owing to the nature of this research, the participants of this study did not agree to their data being shared publicly; therefore, supporting data are not available.

Acknowledgments: The authors appreciate the provision by the National Centers for Environmental Prediction (NCEP) of the National Oceanic and Atmospheric Administration (NOAA) for the source code for the WAVEWATCH-III (WW3) model supplied free of charge. The authors also thank the European Centre for Medium-Range Weather Forecasts (ECMWF) for providing interim wind data at $0.5^{\circ}$ grids that can be openly downloaded from http:/ / www.ecmwf.int (accessed on 19 October 2021). The water depth from General Bathymetry Chart of the Oceans (GEBCO) data was obtained 
from ftp.edcftp.cr.usgs.gov (accessed on 19 October 2021). The current data from the Climate Forecast System Version 2 (CFSv2) were collected from http:/ / cfs.ncep.noaa.gov (accessed on 19 October 2021). Additionally, the authors appreciate the National Satellite Ocean Application Service (NSOAS) provided the Chinese-French Oceanography SATellite (CFOSAT) data through an authorized account via https:/ / osdds.nsoas.org.cn (accessed on 19 October 2021).

Conflicts of Interest: The authors declare no conflict of interest.

\section{References}

1. Charnock, H. Wind stress on a water surface. Q. J. R. Meteorol. Soc. 1955, 81, 639-640. [CrossRef]

2. Oost, W.A.; Komen, G.J.; Jacobs, C.M.J.; Van Oort, C. New evidence for a relation between wind stress and wave age from measurements during ASGAMAGE. Bound.-Layer Meteorol. 2002, 103, 409-438. [CrossRef]

3. Hsu, S.A. A dynamic roughness equation and its application to wind stress determination at the air-sea interface. J. Phys. Oceanogr. 1974, 4, 116-120. [CrossRef]

4. Wu, J. Wind-stress coefficients over sea surface near neutral conditions-A revisit. J. Phys. Oceanogr. 1980, 10, 727-740. [CrossRef]

5. Smith, S.D. Coefficients for sea surface wind stress, heat flux, and wind profiles as a function of wind speed and temperature. J. Geophys. Res. 1988, 93, 15467-15472. [CrossRef]

6. Donelan, M.A.; Dobson, F.W.; Smith, S.D.; Anderson, R.J. On the dependence of sea surface roughness on wave development. J. Phys. Oceanogr. 1993, 23, 2143-2149. [CrossRef]

7. Roland, A.; Ardhuin, F. On the developments of spectral wave models: Numerics and parameterizations for the coastal ocean. Ocean Dyn. 2014, 64, 833-846. [CrossRef]

8. Tolman, H.L. Treatment of unresolved islands and ice in wind wave models. Ocean Model. 2003, 5, 219-223. [CrossRef]

9. Hu, Y.Y.; Shao, W.Z.; Shi, J.; Sun, J.; Cai, L.N. Analysis of the typhoon wave distribution simulated in WAVEWATCH-III model in the context of Kuroshio and wind-induced current. J. Oceanol. Limnol. 2020, 38, 1692-1710. [CrossRef]

10. Sun, Z.F.; Shao, W.Z.; Yu, W.P.; Li, J. A study of wave-induced effects on sea surface temperature simulations during typhoon events. J. Mar. Sci. Eng. 2021, 9, 622. [CrossRef]

11. WAVEWATCH III Development Group. User Manual and System Documentation of WAVEWATCH III Version 6.07. EMC/MMAB/NCEPAA, MMAB Contribution No. 333; 2019. Available online: https://github.com/NOAA-EMC/WW3/wiki/ Manual (accessed on 19 October 2021).

12. Rogers, W.E.; Hwang, P.; Wang, W.D. Investigation of wave growth and decay in the SWAN model: Three regional-scale applications. J. Phys. Oceanogr. 2003, 33, 366-389. [CrossRef]

13. Yang, Z.H.; Shao, W.Z.; Ding, Y.Y.; Shi, J.; Ji, Q.Y. Wave simulation by the SWAN model and FVCOM considering the sea-water level around the Zhoushan islands. J. Mar. Sci. Eng. 2020, 8, 783. [CrossRef]

14. Sun, Z.F.; Shao, W.Z.; Wang, W.L.; Yu, W.P.; Shen, W. Analysis of wave-induced Stokes transport effects on sea surface temperature simulations in the Western Pacific Ocean. J. Mar. Sci. Eng. 2021, 9, 834. [CrossRef]

15. Hu, Y.; Shao, W.Z.; Wei, Y.L.; Zuo, J.C. Analysis of typhoon-induced waves along typhoon tracks in the western North Pacific Ocean, 1998-2017. J. Mar. Sci. Eng. 2020, 8, 521. [CrossRef]

16. The Wamdi Group. The WAM Model-A third generation ocean wave prediction model. J. Phys. Oceanogr. 1988, 18, 1775-1810. [CrossRef]

17. Tolman, H.L.; Booij, N. Modeling wind waves using wave number direction spectra and a variable wavenumber grid. Glob. Atmos. Ocean. Syst. 1998, 6, 295-309.

18. Tolman, L. A third-generation model for wind waves on slowly varying, unsteady, and inhomogeneous depths and currents. J. Phys. Oceanogr. 1991, 21, 782-797. [CrossRef]

19. Holthuijsen, L. The Continued Development of the Third-Generation Shallow Water Wave Model 'SWAN'; Tu Delft Department of Hydraulic Engineering: Delft, The Netherlands, 2001; Volume 32, pp. 185-186.

20. Chu, P.; Qi, Y.; Chen, Y.; Shi, P.; Mao, Q. South china sea wind-wave characteristics. Part I: Validation of Wavewatch-III using TOPEX/Poseidon data. J. Atmos. Ocean. Tech. 2004, 21, 1718-1733. [CrossRef]

21. Wang, Y.; Jiang, X.W. Improvement and application of a saturation based wave dissipation function in SWAN model. Acta Oceanologica. Sin. 2012, 31, 24-32. [CrossRef]

22. Rascle, N.; Ardhuin, F. A global wave parameter database for geophysical applications. Part 2: Model validation with improved source term parameterization. Ocean Model. 2013, 70, 174-188. [CrossRef]

23. Sheng, Y.X.; Shao, W.Z.; Li, S.Q.; Zhang, Y.M.; Yang, H.W.; Zuo, J.C. Evaluation of typhoon waves simulated by WaveWatch-III model in shallow waters around Zhoushan islands. J. Ocean Univ. China 2019, 18, 109-119. [CrossRef]

24. Shao, W.Z.; Sheng, Y.X.; Li, H.; Shi, J.; Ji, Q.Y.; Tan, W.; Zuo, J.C. Analysis of wave distribution simulated by WAVEWATCH-III model in typhoons passing Beibu Gulf, China. Atmosphere 2018, 9, 265. [CrossRef]

25. Fan, Y.L.; Rogers, W.E. Drag coefficient comparisons between observed and model simulated directional wave spectra under hurricane conditions. Ocean Model. 2016, 102, 1-13. [CrossRef]

26. Garratt, J.R. Review of drag coefficients over oceans and continents. Mon. Weather Rev. 1977, 105, 915-929. [CrossRef]

27. $\mathrm{Wu}, \mathrm{J}$. Variations of whitecap coverage with wind stress and water temperature. J. Phys. Oceanogr. 1988, 18, 1448-1453. [CrossRef] 
28. Guan, C.; Xie, L. On the linear parameterization of drag coefficient over sea surface. J. Phys. Oceanogr. 2004, 34, $2847-2851$. [CrossRef]

29. Donelan, M. On the decrease of the oceanic drag coefficient in high winds. J. Geophys. Res. 2018, 123, 1485-1501. [CrossRef]

30. Tsai, Y.S.; Chang, W.T.; Yu, C.M.; Yang, W.C. General sea state and drag coefficient observed near shore in Taiwan Strait. Procedia IUTAM 2018, 26, 204-213. [CrossRef]

31. Wang, Z.F.; Guo, Y.J.; Cui, J.N.; Dong, S.; Wu, K.J. Effect of the drag coefficient on a typhoon wave model. J. Oceanol. Limnol. 2019, 37, 1795-1840. [CrossRef]

32. Xu, Y.; Liu, J.Q.; Xie, L.L.; Sun, C.R.; Liu, J.P.; Li, J.Y. China-France Oceanography Satellite (CFOSAT) simultaneously observes the typhoon-induced wind and wave fields. Acta Oceanol. Sin. 2019, 38, 158-161. [CrossRef]

33. Shao, W.Z.; Sheng, Y.X.; Sun, J. Preliminary assessment of wind and wave retrieval from Chinese Gaofen-3 SAR imagery. Sensors 2017, 17, 1705. [CrossRef]

34. Zhu, J.T.; Dong, X.L.; Lin, W.M.; Zhu, D. A preliminary study of the calibration for the rotating fan-beam scatterometer on CFOSAT. IEEE J. Sel. Topics Appl. Earth Observ. Remote Sens. 2015, 8, 460-470. [CrossRef]

35. Hauser, D.; Tison, C.; Amiot, T.; Delaye, L.; Corcoral, N.; Castillan, P. SWIM: The first spaceborne wave scatterometer. IEEE. Trans. Geosci. Remote. 2017, 55, 3000-3014. [CrossRef]

36. Wang, L.L.; Ding, Z.Y.; Zhang, L.; Yan, C. CFOSAT-1 realizes first joint observation of sea wind and waves. Aerosp. China 2019, 20, 22-29.

37. Hauser, D.; Tourain, C.; Hermozo, L.; Alraddawi, D.; Aouf, L.; Chapron, B.; Dalphinet, A.; Delaye, L.; Dalila, M.; Dormy, E.; et al. New observations from the SWIM radar on-board CFOSAT: Instrument validation and ocean wave measurement assessment. IEEE Trans. Geosci. Remote 2020, 59, 5-26. [CrossRef]

38. Wang, J.K.; Aouf, L.; Dalphinet, A.; Zhang, Y.G.; Xu, Y.; Hauser, D.; Liu, J.Q. The wide swath significant wave height: An innovative reconstruction of significant wave heights from CFOSAT SWIM and scatterometer using deep learning. Geophys. Res. Lett. 2021, 48, e2020GL091276. [CrossRef]

39. Molteni, F.; Buizza, R.; Palmer, T.; Petroliagis, T. The ECMWF ensemble prediction system: Methodology and validation. Q. J. R. Meteor. Soc. 2010, 122, 73-119. [CrossRef]

40. Zheng, C.W.; Zhou, L.; Huang, C.F.; Shi, Y.L.; Li, J.X.; Li, J. The long-term trend of the sea surface wind speed and the wave height (wind wave, swell, mixed wave) in global ocean during the last 44 a. Acta Oceanol. Sin. 2013, 32, 1-4. [CrossRef]

41. Zheng, C.W.; Liang, B.C.; Chen, X.; Wu, G.X.; Sun, X.F.; Yao, J.L. Diffusion characteristics of swells in the north Indian Ocean. J. Ocean Univ. China 2021, 19, 479-488. [CrossRef]

42. Zhang, J.; Wang, W.L.; Guan, C.L. Analysis of the global swell distributions using ECMWF re-analyses wind wave data. J. Ocean Univ. China 2011, 10, 325-330. [CrossRef]

43. Bi, F.; Song, J.B.; Wu, K.J.; Xu, Y. Evaluation of the simulation capability of the Wavewatch III model for Pacific Ocean wave. Acta Oceanol. Sin. 2015, 34, 43-57. [CrossRef]

44. Sterl, A.; Caires, S. Climatology variability and extrema of ocean waves-The web-based KNMI/ERA-40 wave atlas. Int. J. Climatol. 2005, 25, 963-977. [CrossRef]

45. Caires, S.; Sterl, A. Validation and non-parametric correction of significant wave height data from the ERA-40 reanalysis. J. Atmos. Ocean. Tech. 2005, 22, 443459. [CrossRef]

46. Stopa, J.E.; Cheung, K.F. Intercomparison of wind and wave data from the ECMWF reanalysis interim and the NECP climate forecast system reanalysis. Ocean Model. 2014, 75, 65-83. [CrossRef]

47. Holland, G.J. An analytic model of the wind and pressure profiles in hurricanes. Mon. Weather Rev. 1980, 108, 1212-1218. [CrossRef]

48. Tolman, H.L.; Chalikov, D.V. Source terms in a third-generation wind wave model. J. Phys. Oceanogr. 1996, 26, 2497-2518. [CrossRef]

49. Madsen, P.A.; Sørensen, O.R. Bound waves and triad interactions in shallow water. Ocean Eng. 1993, 20, 359-388. [CrossRef]

50. Hasselmann, S.; Hasselmann, K. Computations and parameterizations of the nonlinear energy transfer in a gravity-wave spectrum. part I: A new method for efficient computations of the exact nonlinear transfer integral. J. Phys. Oceanogr. 1985, 15, 1369-1377. [CrossRef]

51. Donelan, M.A.; Curcic, M.; Chen, S.S.; Magnusson, A.K. Modeling waves and wind stress. J. Geophys. Res. 2012, 117, C00J23. [CrossRef]

52. Hasselmann, D.E.; Dunckel, M.; Ewing, J.A. Directional wave spectra observed during JONSWAP 1973. J. Phys. Oceanogr. 1980, 10, 1264-1280. [CrossRef]

53. Jiang, H.Y.; Mironov, A.; Ren, L.; Babanin, A.V.; Wang, J.; Mu, L. Validation of wave spectral partitions from SWIM instrument on-board CFOSAT against in situ data. IEEE. Trans. Geosci. Remote Sens. 2021, 1-13. [CrossRef]

54. Smith, S.D.; Banke, E.G. Variation of the sea surface drag coefficient with wind speed. Q. J. R. Meteor. Soc. 1975, 101, 665-673. [CrossRef]

55. Zhao, D.L.; Li, M.X. Dependence of wind stress across an air-sea interface on wave states. J. Oceanogr. 2018, 75, 207-223. [CrossRef]

56. Fairall, C.W.; Bradley, E.F.; Hare, J.E.; Grachev, A.A.; Edson, J.B. Bulk parameterization of air-sea fluxes: Updates and verification for the COARE algorithm. J. Climate 2003, 16, 571-591. [CrossRef] 
57. Taylor, P.K.; Yelland, M.J. The dependence of sea surface roughness on the height and steepness of the waves. J. Phys. Oceanogr. 2001, 31, 572-590. [CrossRef]

58. Vickers, D.; Mahrt, L.; Andreas, E.L. Estimates of the 10-m neutral sea surface drag coefficient from aircraft eddy covariance measurements. J. Phys. Oceanogr. 2013, 43, 301-310. [CrossRef]

59. Hwang, P. A note on the ocean surface roughness spectrum. J. Atmos. Ocean. Tech. 2011, 28, 436-443. [CrossRef]

60. Holthuijsen, L.; Powell, M.; Pietrzak, J.D. Wind and waves in extreme hurricanes. J. Geophys. Res. 2012, 117, C09003. [CrossRef]

61. Troitskaya, Y.I.; Ermakova, O.S.; Kandaurov, A.A.; Kozlov, D.S.; Sergeev, D.A.; Zilitinkevich, S.S. Non-monotonous dependence of the ocean surface drag coefficient on the hurricane wind speed due to the fragmentation of the ocean-atmosphere interface. Dokl. Earth Sci. 2017, 477, 1373-1378. [CrossRef]

62. Allahdadi, M.; Li, C. Numerical simulation of Louisiana shelf circulation under Hurricane Katrina. J. Coast. Res. 2018, 34, 67-80. [CrossRef]

63. Allahdadi, M.; Chaichitehrani, N.; Allahyar, M.; Mcgee, L. Wave spectral patterns during a historical cyclone: A numerical model for Cyclone Gonu in the Northern Oman Sea. Open J. Fluid Dynam. 2017, 7, 131-151. [CrossRef]

64. Shao, W.Z.; Yu, W.P.; Jiang, X.W.; Shi, J.; Wei, Y.L.; Ji, Q.Y. Analysis of wave distributions using the WAVEWATCH-III model in the Arctic Ocean. J. Ocean Univ. China 2021, 1-3. [CrossRef] 